\title{
Proteostasis in Huntington's disease: disease mechanisms and therapeutic opportunities
}

\section{Rachel J. Harding ${ }^{1}$ and Yufeng Tong ${ }^{1,2}$}

${ }^{1}$ Structural Genomics Consortium, University of Toronto, MaRS South Tower, Suite 700, 101 College

Street, Toronto, Ontario M5G1L7, Canada

${ }^{2}$ Department of Pharmacology and Toxicology, University of Toronto, Toronto, Ontario M5G 1L7, Canada

\begin{abstract}
:
Many neurodegenerative diseases are characterised by impairment of protein quality control mechanisms in neuronal cells. Ineffective clearance of misfolded proteins by the proteasome, autophagy pathways and exocytosis leads to accumulation of toxic protein oligomers and aggregates in neurons. Toxic protein species affect various cellular functions resulting in the development of a spectrum of different neurodegenerative proteinopathies, including Huntington's disease (HD). Playing an integral role in proteostasis, dysfunction of the ubiquitylation system in HD is progressive and multi-faceted with numerous biochemical pathways affected, in particular the ubiquitin proteasome system and autophagy routes for protein aggregate degradation. Unravelling the molecular mechanisms involved in HD pathogenesis of proteostasis provides insight in disease progression in HD as well as possible therapeutic avenues. Recent developments of potential therapeutics are discussed in this review.
\end{abstract}

\section{Keywords:}

Huntington's Disease; Neurodegenerative Diseases; Autophagy; Proteostasis; Proteasomal Degradation 


\section{Huntington's Disease:}

Huntington's disease (HD) is a devastating inherited neurodegenerative disorder resulting in a diverse range of behavioural, cognitive and physical symptoms, including the renowned motor disorder, chorea. These symptoms are the result of selective neurodegeneration that occurs preferentially in the striatum ${ }^{1}$. The incidence of HD in different populations around the world is varied with epidemiological reports finding between 0.42 to 17.2 cases per $100,000^{2}$. Clinical diagnosis of motor onset typically occurs in the prime of adult life and symptoms progress inexorably, leading to chronic deterioration of patient health. The median timeframe from the manifestation of motor function symptoms to patient death is approximately 18 years ${ }^{3}$. No cures are currently available.

$\mathrm{HD}$ is an autosomal dominant disease caused by a CAG trinucleotide repeat expansion in exon 1 of the huntingtin gene $(H T T)^{4}$. In healthy individuals, HTT has a CAG tract length of approximately 18 repeats $^{5}$. Repeat lengths above a critical threshold of 35 CAG triplets in HTT are defined as diseasecausing alleles ${ }^{6}$. At above 40 repeats, the disease is considered highly penetrant and an increased CAG repeat length is correlated with the decreased age of symptom onset as well as the increased rate of pathogenesis ${ }^{7}$.

The CAG expansion in HTT, translates to an expansion of the polyglutamine (polyQ) tract at the Nterminus of huntingtin (HTT). The polyQ expansion mutation is often ascribed as giving a toxic gain-offunction phenotype in HD. PolyQ expanded HTT is attributed to cytotoxicity and biochemical dysfunction observed in HD models and patients. Significant impairment of the proteostasis network ${ }^{8}$, dysregulated transcription ${ }^{9}$, mitochondrial toxicity ${ }^{1011}$, cellular energy imbalance ${ }^{12}$, synaptic dysfunction ${ }^{13}$ and axonal transport impairment ${ }^{11}$ are thought to result from aberrant forms of the HTT protein. These cellular phenotypes may be observed in premanifest and prodromal patients, and is exemplified by brain atrophy of patients, sometimes prior to clinical diagnosis ${ }^{14}$. 


\section{Mutant Huntingtin Protein:}

$\mathrm{HTT}$ is a $348 \mathrm{kDa}$ protein predicted to be composed almost exclusively of alpha-helices, organised into namesake HEAT (Huntingtin, elongation factor 3 (EF3), protein phosphatase 2A (PP2A), and the yeast kinase TOR1) repeats ${ }^{15}$. HEAT repeats are interspersed with unstructured regions, often containing cleavage sites for proteolytic fragmentation as well as post-translational modifications (PTMs) ${ }^{1617}$. PTMs, in particular phosphorylation motifs at the $\mathrm{N}$-terminus, are thought to be responsible for large-scale conformational changes of the protein as well as alterations in protein-protein interaction networks ${ }^{18}$.

Cells ${ }^{19}$, model organisms ${ }^{20}$ and patients ${ }^{21}$ expressing CAG expanded versions of HTT can generate large protein clusters, fibrils and inclusions, some of which are large enough to be visualised by light microscopy and are composed of 100,000 s of HTT molecules ${ }^{21,22}$. Aggregation has consistently been shown to be dependent on the polyQ expansion of HTT in a range of different experimental systems and environments ${ }^{23-25}$. However, low resolution (> $30 \AA \AA$ ) negative stain electron microscopy (EM) data of recombinant full-length HTT protein reveals a globular spherical structure ${ }^{26}$ with no significant differences between Q23 (general population) and Q46 or Q78 (disease population) HTT EM envelopes resolved at this resolution suggesting aggregation of poly Q expanded HTT is a complex process requiring specific cellular conditions. Unpublished but higher resolution negative stain and cryo-EM data, both around $15 \AA$ resolution, reveals a curved architecture with a central cavity which varies in size dependent on sample preparation methods, in particular the concentration of cross-linking reagent used in the gradient fixation ultracentrifugation step, but not due to polyQ length ${ }^{27}$. Beyond this, limited data is available in the published literature with respect to the structure of the HTT protein, thus it remains unclear precisely how the polyQ expansion might affect the HTT protein structure and, in turn, its propensity to form higher order oligomers. 
Aggregate species are present in many flavours in various HD models and post-mortem tissue samples although which species of aggregates are damaging or protective to cells remains controversial in the field ${ }^{198}$. The function of HTT, in either the wild type or the disease state, is still poorly understood. It is thought that HTT acts as a scaffolding protein ${ }^{2829}$, involved in many protein-protein interactions and in the formation of multi-protein complexes. Dysregulation of this interaction network by the polyQ expansion and subsequent aggregation is thought to be responsible for the resultant phenotype ${ }^{3031}$, sometimes described as a gain-of-function. Most published work to date on HTT oligomers and their associated neuropathology has focussed on exon1 proteins ${ }^{2833}$. HTT is cleaved by a variety of caspases, calpains and endopeptidases to yield a variety of $\mathrm{N}$-terminal fragments including a short sequence encoding exon 1 of the protein, corresponding to approximately the first 90 amino acids depending on the polyQ expansion length contained in this fragment ${ }^{2833}$. Exon 1 is comprised of the $\mathrm{N}$-terminal 17 amino acids (N17), the polyQ tract and then a 51-residue proline-rich domain (PRD). The structure of $\mathrm{N} 17$ is alpha-helical and the exon 1 protein adopts condensed disordered state at high concentrations ${ }^{34}$. The exon 1 structure is altered by polyQ expansion although there is no consensus on which morphology of exon 1 represents the toxic aggregate species. Whilst exon1 HTT protein fragments have been shown to be a degradation product in many HD models and their aggregation underlies disease pathology ${ }^{3536}$, larger fragments and full-length HTT are almost certainly involved in this oligomerisation process in human patients ${ }^{37}$ with post-translational modification, particularly phosphorylation, of HTT playing a crucial role in aggregation and toxicity ${ }^{38}$. To date, the precise pathogenic mechanism which renders the HTT protein functional with a polyQ tract less than 35 glutamines, but devastatingly damaging above a threshold of 40 glutamines, and which HTT species give rise to this breach in polyQ threshold, remains a fundamental yet unanswered question in the HD field.

\section{Cellular proteostasis}


Disruption of protein homeostasis, or proteostasis, is a hallmark of many neurodegenerative diseases, such as Alzheimer's disease and Parkinson's disease as well as HD. Proteostasis is the precise balance of protein expression in cells at the correct concentrations, in the correct localisation and with the appropriate conformation ${ }^{39}$. Central to proteostasis is the post-translational modification of proteins, by covalent attachment of ubiquitin i.e. ubiquitylation (Figure $\mathbf{1})^{40}$. Ubiquitylation is the tagging of the substrate lysine by a three-enzyme cascade comprised of a ubiquitin activating enzyme (E1), a conjugating enzyme (E2) and a ubiquitin ligase (E3). E3 ligases are believed to be key in substrate recognition. Several E3 ligases have been reported to be involved in HTT ubiquitylation, including WWP1 ${ }^{41}, \mathrm{UBE}^{4} \mathrm{~A}^{42}, \mathrm{HACE} 1^{43}, \mathrm{CHIP} 44,45, \operatorname{Hrd1}^{46}$ and Parkin ${ }^{47}$ in mammals and Ltn $1^{4846}$ in yeast. Tagged ubiquitin can be further modified at one of its seven lysine residues in the ubiquitin molecule (K6, K11, $\mathrm{K} 27, \mathrm{~K} 29, \mathrm{~K} 33, \mathrm{~K} 48$ and $\mathrm{K} 63$ ) as well as the $\mathrm{N}$-terminal methionine (M1) to form polyubiquitin chains of different linkages ${ }^{49}$. The various lysine residues of the tagged ubiquitin can be further modified to form a polyubiquitin chain. The covalently attached ubiquitin or ubiquitin chain can be removed by a family of enzymes called deubiquitinases (DUBs). Surprisingly, few DUBs have been reported to deubiquitinate HTT. ATXN3, a DUB that itself contains a polyQ tract, is the only DUB known to target $\mathrm{HTT}^{50,51}$ besides UPS. Monoubiquitination or ubiquitin conjugation of proteins by differernt linkages of chainsare recognised by a range of proteins containing ubiquitin binding domains (UBDs) or ubiquitin-interacting motifs (UIMs) and are essential in numerous cell signalling pathways. Ubiquitylated proteins can be targeted for degradation via the ubiquitin proteasome system (UPS) or lysosome/autophagy pathway. Ubiquitin-like modification, such as sumoylation ${ }^{52}$, is also known to play critical role of HTT degradation.

A complete understanding of these pathways and how they may be altered in HD patients and disease models can illuminate possible strategies for increasing degradation of mutant HTT (mHTT) through therapeutic intervention to alleviate symptoms. This review aims to describe recent findings in 
this area, with a focus on ubiquitination, as well as a discussion of the tractability to develop successful therapeutics for HD modulating these pathways.

\section{Ubiquitin Proteasome System function in HD}

The ubiquitin proteasome system (UPS) preferably degrades substrate proteins tagged with K48linkage polyubiquitin chain although monoubiquitination was recently also found to target UPS $^{53}$ besides its function in protein localization and signaling. Pathogenic forms of HTT can be labelled with ubiquitin cross-reacting antibodies ${ }^{21,22}$ implying that they may be substrates for proteasomal degradation. Inclusion bodies (IBs) containing $\mathrm{mHTT}$ can also be labelled with antibodies against proteasome components suggesting direct recruitment of the UPS to some HTT aggregates ${ }^{54}$. As UPS function is widely reported to be diminished in a variety of $\mathrm{HD}$ models ${ }^{55,56}$, it has been suggested that proteasome sequestration by HTT aggregates is responsible for changes in UPS activity. Disassembly of the proteasome into its substituent components which are then sequestered by HTT aggregates, is also postulated as a mechanism to affect UPS activity ${ }^{57}$. However, studies investigating UPS activity with different proteasome assemblies in the presence of HTT IBs failed to detect significant changes in UPS activity $^{58}$. The sequestration of proteasomes to ubiquitin conjugated IBs is likely dynamic and reversible ${ }^{59}$ and a number of studies show that proteasomes are still able access substrates in the presence of polyQ expanded HTT species. Recombinantly expressed polyQ expanded HTT aggregates were found to not inhibit UPS function in vitro ${ }^{60}$ whilst extracted aggregate filaments $\mathrm{do}^{58}$, suggesting that perhaps the ubiquitylation of the aggregates in vivo plays a crucial role. It was postulated polyQ stretches may clog the proteasome given that glutamine does not strictly fit into any of these categories. Contradictory studies show polyQ fragments blocking the proteasome ${ }^{61,62}$ whilst other show complete degradation of HTT exon1 $1^{63,64}$. As such, it is difficult to draw definitive conclusions on UPS activity modulation or a mechanism by which this might occur in HD models, particularly one which is an accurate representation of UPS function in HD patients. 
Many of these studies take a simplified view of UPS activity without assessing the complex E1, E2 and E3 ubiquitin-ligating processes which precede UPS degradation of HTT, nor the complex series of cell signalling pathways which may alter UPS function and processivity. Although there are only 8 subtypes of E1 and 40 E2 encoded in the human genome, there are more than $600 \mathrm{E} 3$ ligases reflecting the highly-specialised functions of this group of enzymes. In the case of HTT, UBE3A has been shown to specifically target HTT fragments for ubiquitination and degradation ${ }^{4265}$. Overexpression of UBE3A, a K48-specific E3 ligase, is able to promote UPS degradation of polyQ expanded HTT and reduce K63mediated ubiquitination. Clearance of HTT by UBE3A-mediated ubiquitination in these studies was shown to be age-dependent in HD knock-in mouse models, postulating a mechanism for the agedependency of HD symptoms and their progression. Yet, the recent finding that both WWP1 $1^{41}$, another E3 ligase capable of forming K11-, K48- and K63-polyubiquitin chains, and ATXN3, a DUB that prefers K63-chain substrate, in HTT ubiquitylation, suggests there may be formation of heterotypic polyubiquitin chains ${ }^{66}$ that will complicates the degradation of HTT by UPS.

\section{HD modulation of the chaperone and autophagy machinery}

HD has been shown to modulate autophagy function to have both toxic and protective effects on cells. Recognition of cargo by autophagosomes ${ }^{67}$ as well as subsequent axonal transport and substrate degradation ${ }^{68}$ are all diminished in HD. Rhes GTPase is required for autophagy as it interacts with Beclin1 to reduce the inhibitory binding of Beclin-1 and Bcl-2 but is sequestered and inactivated by binding to polyQ expanded $\mathrm{HTT}^{69}$. This reduces autophagy function in the striatum where Rhes is expressed, a key tissue affected by HD. Conversely, mHTT also sequesters negative regulator of autophagy mTOR (mammalian target of rapamycin) inducing a higher rate of flux of autophagy and protecting against polyQ expanded HTT cytotoxicity ${ }^{70}$. mTOR phosphorylates mammalian autophagy-initiating kinase ULK1 at Ser 757, preventing its interaction and subsequent phosphorylation by AMPK at Ser 317 and Ser 777, which activate ULK1 $1^{71} \|$. This coordinated regulation by phosphorylation is linked to the nutrient status 
of the cell with mTOR signalling prevailing under conditions of nutrient sufficiency and AMPK signalling in conditions of glucose starvation. Autophagy induction has been shown to relieve cellular toxicity posed by $\mathrm{mHTT}$ in the absence of UPS activity ${ }^{72,73}$. This study achieved increased autophagic flux through the overexpression of HDAC6, a cytosolic deacetylase which intersects both the autophagy and the UPS pathways and promotes aggresomal clearance through tubulin deacetylation.

Approximately 90 chaperones and $\sim 250$ co-chaperones comprise the human chaperome, a class of proteins categorised into families by their dependency on ATP for function as well as their molecular weight e.g. HSP40, HSP70 and HSP90 representing proteins of $40 \mathrm{kDa}, 70 \mathrm{kDa}$ and $90 \mathrm{kDa}$ respectively. Chaperones function to promote proper folding and localisation of proteins and function in response to stresses which might disrupt protein structure or compartmentalisation in cells. Chaperones prevent aberrant protein interactions to hinder protein aggregation and the formation of inclusion bodies or other aggregate species but can also promote degradation of damaged or misfolded proteins. Cochaperones such as parkin, CHIP (also an E3 ligase) and BAG3 have varied roles in assisting the proteostatic functions of chaperones.

HSP70 and HSP90 play central roles in protein quality control with HSP90 stabilising client proteins and inhibiting their ubiquitination whilst conversely HSP70 promotes CHIP-dependent ubiquitination and proteasomal degradation ${ }^{74}$. HSP90 has been shown to co-immunoprecipitate (IP) with both wildtype and polyQ expanded HTT, with chaperone p23 also present in both of these pull-downs ${ }^{75}$. Whilst fulllength HTT has been shown to be a client of HSP90, direct binding of HSP90 to exon1 has not been demonstrated so the site of recruitment is unknown. HSP70 cross-reacting antibodies do bind HTT $\mathrm{IBs}^{76,77}$ and HSP70 over-expression can suppress aggregation and toxicity in some HD models ${ }^{77-79}$. Deletion of HSP70 alleles in a R6/2 HD mouse model background increases IB size as well as having deleterious effects on the physical, behaviourial and neuropathological measures ${ }^{80}$. CHIP and Parkin are 
implicated as E3 ligases of $\mathrm{mHTT}$ degradation. Both Co-IP with $\mathrm{mHTT}$ and CHIP has also been shown to increase mutant exon1 ubiquitination and degradation ${ }^{45}$. HSP70 enhances Parkin binding and ubiquitination in vitro ${ }^{81}$. Overall, it is likely $\mathrm{mHTT}$ is a HSP9O client protein and that it is regulated by HSP70/90-based chaperone machinery.

Bcl-2-associated athanogene 3 (BAG3) is a HSP70 co-chaperone which functions in concert with HSP70, HSPB8 and p62/SQSTM1 to target aggregation-prone proteins for autophagic degradation ${ }^{82}$. BAG3 is crucial for HSPB8 activity in preventing polyQ expanded HTT aggregation and together, BAG3HSPB8 promote and facilitate the clearance of polyQ expanded $\mathrm{HTT}^{83}$. Whilst neither the BAG nor WW domains are essential for mHTT clearance indicating HSP70 is not critical for degradation via this route ${ }^{84}$, the PxxP region binding to dynein is required for autophagic degradation of HTT aggregates. BAG3 overexpression has both anti-apoptotic effects and promotes the disposal of aggregate prone proteins, both of which would have positive effects in the case of HD.

\section{Therapeutic Strategies for HD targeting ubiquitin pathways:}

A major focus area for disease-modifying therapeutic development in HD is to lower the levels of mHTT in the cell to alleviate neuropathology ${ }^{85}$. The monogenic inheritance of HD does favour therapeutic approaches which reduce expression of the $\mathrm{mHTT}$ allele by targeting DNA and RNA with gene silencing technologies ${ }^{86,87}$. Alternative efforts have focussed on lowering $\mathrm{mHTT}$ by increasing the degradation of mHTT through increased flux of UPS and autophagic pathways.

\section{Therapeutic approaches in HD targeting UPS}

Bortezimib is a well-characterised UPS inhibitor, which binds directly to the proteasome core particle to inhibit protein degradation, and is used in the clinic for treatment of various cancers ${ }^{88,89}$. Prolonged treatment of patients has been observed to result in peripheral neuropathy indicating the connection between UPS dysfunction and neurotoxicity ${ }^{88}$. A diverse category of compounds are 
reported to activate UPS function. Most of these molecules act indirectly to increase UPS flux by modulating upstream effector cellular pathways linked to correcting redox and mitochondrial dysregulation in HD which inhibits UPS. For example, sulforaphane increases both proteasome and autophagy activity levels in vivo by activating the Keap1-Nrf2-ARE pathways and inhibiting MAPK and NF-kB pathways, as shown in a number of different HD mouse models ${ }^{90,91}$. Sulforaphane was also shown to reduce quinolinic acid mitochondrial dysfunction in rat striatum, conferring a neuroprotective effect $^{92}$. Rolipram inhibits phosphodiesterase 4 thus activating protein kinase $A$ to enhance proteasome activity and in a HD mouse model was shown to alleviate symptoms of neuronal dysfunction ${ }^{93}$. Recently, a series of compounds which enhance proteasome activity were identified using a UPS activity probe $\mathrm{e}^{94,95}$ with p38 MAPK inhibitor PD169316 proving the most potent. Activation of the UPS with these small molecules showed increased proteasome activity and aggregate clearance in a Parkinson's disease model. PD169316 is untested in an HD model but p38 inhibition has been shown to be neuroprotective in $\mathrm{HD}^{96}$. Amiloride and its derivative benzamil are also able to rescue acid-sensing ion channel (ASIC)dependent acidotoxicity which inhibits UPS function in HD models. Benzamil treatment facilitates proteasomal degradation of polyQ expanded HTT in both cellular and mouse models of HD ${ }^{97}$. USP14 is a negative regulator of UPS through the deubiquitination of UPS substrates. USP14 inhibition by IU1 also enhances proteasomal degradation ${ }^{98}$ but details of the effect of IU1 on HD models have yet to be described in the published literature despite positive reports for upregulation of UPS activity in models of Alzheimers disease ${ }^{99,100}$.

\section{Therapeutic approaches in HD targeting Autophagy}

mTOR inhibitors with autophagy induction properties can be classified as ATP-competitive e.g. Torin1 or non-ATP-competitive e.g. rapamycin. ATP-competitive inhibitors face issues with toxicity due to their inhibition of mTORC1, mTORC2 and sometimes PI3K so are usually confined to animal studies only. Rapamycin and its derivatives have been shown to improve HD phenotypes; in particular CCI-779 
was shown to reduce $\mathrm{mHTT}$ aggregate load in HD mouse models $\mathrm{s}^{70,101}$. Trehalose acts to activate AMPK by inhibiting glucose transporters leading to glucose starvation conditions ${ }^{102,103}$ which induce autophagy to mitigate toxicity exhibited by polyQ expanded HTT in cell and mouse models ${ }^{104,105}$. Trehalose was also shown to reverse neurodegenerative phenotypes induced by UPS inhibition, in both normal and HD patient fibroblasts ${ }^{106}$. Rilmenidine is an mTOR-independent macroautophagy inducer and improves motor function and the clearance of $\mathrm{mHTT}$ in HD mouse models ${ }^{107}$. Lithium induces mTOR-independent autophagy through inhibition of inositol monophophatase therefore reducing inositol and IP3 levels which would inhibit autophagy ${ }^{108}$. This has been shown to help clear mHTT in drosophila HD models ${ }^{109}$. Berberine has also been reported to show efficacy in HD models, and is postulated to induce autophagy via AMPK activation ${ }^{110,111}$. Many other molecules including clonidine ${ }^{112}$, modulate cyclic AMP or inositol triphosphate to induce autophagy and ameliorate phenotypes in HD animal models. Calpain has been described as a rational target for increasing autophagic flux of mHTT. RNAi experiments in rodents in which calpain was knocked down showed reduced HTT aggregate burden ${ }^{113}$ and were similar results were observed in transgenic mice which overexpressed calpastatin (CAST), the endogenous inhibitor of calpain. Metformin is another AMPK activating inducer of autophagy which has been shown to alleviate mHTT associated cytotoxicity ${ }^{114,115}$. HD patients who are monitored in the Enroll-HD programme (a world-wide observational and longitudinal study of HD patients) who were already taking metformin to treat type II diabetes, were found to have improved cognitive status compared to control patients not on a metformin-regimen ${ }^{116}$. A great number more small molecules targeting these pathways have been described in the literature but have yet to show efficacy in vivo ${ }^{117}$. Combination therapies which simultaneously upregulate autophagy through both the mTOR and mTOR-independent dependent pathways have been shown to have synergistic effects on alleviating mHTT associated toxicity. Cooperation has been demonstrated with trehalose-rapamycin ${ }^{104}$ as well as lithium-rapamycin ${ }^{101}$ 
combination treatments in HD models although deleterious side-effects are postulated to worsen in the long-term for these treatment regimens.

\section{Therapeutic approaches in HD targeting Chaperone proteins}

HSP90 inhibition is an attractive strategy to treat proteinopathies given its ability to stabilise client proteins, of which mHTT is one ${ }^{75}$. It was shown that the co-IP of HSP9O and $\mathrm{mHTT}$ is abrogated in the presence of HSP9O inhibitors and that $\mathrm{mHTT}$ is ubiquitinated and then degraded in a dose-dependent manner with HSP90 inhibitor. HSP90 inhibitors also reduce mutant exon1 aggregation and toxicity in a variety of HD models ${ }^{77,78,118}$ due to transcription factor heat-shock factor 1 (HSF1) mediated increases in chaperone expression ${ }^{119,120}$. HSP90 inhibitor geldanamycin competes with ATP for binding HSP9O and therefore inhibits the binding and stabilising of $\mathrm{mHTT}^{78}$. 17-DMAG and 17-AAG, less toxic geldanamycin derivatives with more favourable pharmacokinetic properties, were also shown to induce expression of molecular chaperones and inhibit polyQ expanded HTT aggregation in cells and Drosophila models of HD respectively ${ }^{118,120}$ as well as to cross the blood-brain barrier in Alzheimers models ${ }^{121}$. HSP90 isoformspecific inhibitors were shown to have improved tolerability compared to pan-HSP9O inhibitors and were also shown to be orally available, cross the blood-brain barrier and reduce HTT levels in rat brains $^{122}$. Celastrol, a natural product anti-inflammatory agent, binds the C-terminal domain of HSP9O and induces HSP70 expression and protects neurons from polyQ expanded HTT mediated toxicity ${ }^{123}$. HSF-1 activating compounds were shown to suppress polyQ expanded HTT associated neurodegeneration in drosophila HD models through induction of molecular chaperones ${ }^{120}$.

\section{Proteolysis targeting chimera (PROTAC)}

Proteolysis targeting chimera (PROTAC)-based approaches utilise heterobifunctional molecules to simultaneously bind both the protein of interest and a ubiquitin E3 ligase to promote the ubiquitination and degradation of the target molecule ${ }^{124,125}$. By bringing the target protein of interest and E3 ligase into 
close proximity, PROTACs promote the ubiquitination of their target. Following polyubiquitination, the target will be degraded by the proteasome. Recently, a PROTAC-based series of molecules has been described for selective ubiquitination and then degradation of $\mathrm{mHTT}$ via the UPS ${ }^{126}$. Hybrid molecules that link a ligand for cIAP1 (cellular inhibitor of apoptosis protein 1) E3 ligase to ligands for mHTT, were shown to selectively reduce levels of $\mathrm{mHTT}$ through E3 ligase recruitment and proteasome degradation pathways in HD patient-derived fibroblasts. Two HD patient-derived fibroblast cell lines were used in this study expressing Q47 and Q68 $\mathrm{mHTT}$, both obtained from biorepository Coriell ${ }^{127}$, showing that PROTAC-induced degradation could be achieved for adult-onset HD genotypes.

A benefit of the PROTAC approach is that tissue specificity can be exerted by developing molecules which are highly selective in their recruitment of E3 ligases that are only expressed in a certain tissue. The current design of the described HTT-PROTAC molecules used a bestatin moiety to target CIAP1 E3 ligase which is expressed in many different tissues throughout the body although not quite as broadly as UBE3A, the HTT specific E3 ligase ${ }^{65}$. Modifying these PROTAC molecules to bind a brain-specific E3 ligase, such as TRIM9 ${ }^{128}$ or RNF182 129 for example, may reduce systemic effect. It should also be noted that targeting CIAP1 targetting by using bestatin in PROTAC design has been highlighted as problematic due to bestatin causing the degradation of cIAP1 which can in turn trigger apoptosis. Switching the linker of bestatin in the PROTAC design from an ester to an amide, reduces cIAP1 degradation in some systems evaluated although this mechanism is currently not understood and the molecules showed similar affinity for $\mathrm{CIAP}^{130}$. Numerous PROTAC examples illustrate the importance of exploring different linker designs to connect the two functional groups whilst maintaining the desired target protein degradation and further exploration is warranted for HTT-degrading PROTACs too ${ }^{131,132}$.

It should also be noted that whilst the described molecules bind and effectively clear mHTT in HD patient fibroblasts, their binding specificity to different HTT aggregate species or aggregates composed 
of different proteins requires further investigation. The aggregate binding portion of the molecules are composed of previously described ligands phenyldiazenyl benzothiazole (PDB) and benzothiazole-aniline (BTA) which are known to also target amyloid proteins in Alzheimer's disease models ${ }^{133,134}$. Given the heterogeneous and dynamic nature of HTT aggregate species at different stages of the disease progression, developing small molecules that are able to bind and target the disease relevant aggregate species for clearance will be challenging. Perhaps finding binders of the expanded polyQ stretch of HTT will instead confer necessary specificity. However, PDB and BTA have both been shown to cross the blood brain barrier in Alzheimer's studies although the pharmacokinetic properties will need to be evaluated as any change to the E3 ligase ligand or linker region of the molecules are made. Overall this study shows the first proof-of-principle HTT degradation by a PROTAC-based approach in HD patient tissues.

\section{Newly emerging therapeutic targets: ubiquitin pathways implicated in HD GWAS}

HD patient populations with the same CAG repeat length may experience symptom onset in a broad age-range implicating other disease modifying factors. Many recent genome-wide association studies (GWAS) have identified genetic modifiers for the age-of-onset of HD, beyond CAG repeat expansion length, as well as the rate of pathogenic progression. GWAS (GeM-HD consortium, 2015) identified, amongst other modifiers, UBR5 as genetic modifier for $\mathrm{HD}^{135}$. UBR5 is an E3 ubiquitin ligase with key roles in the regulation of the UPS. As discussed, $\mathrm{mHTT}$ is degraded by the UPS via E3 ligase UBE3A, an activity which is down-regulated by UBR5 ${ }^{136}$. This finding in the GWAS implies that pharmacological down-regulation of UBR5 function, perhaps mediated via small molecule targeting, would promote UPS degradation of mHTT. UBR5 is an attractive target in HD as it also regulates PEPCK1 acetylation which plays a role in gluconeogenesis dysfunction in prodromal $\mathrm{HD}^{137}$. Additionally, ubiquitination of ATMIN by UBR5 releases ATM kinase allowing activated ATM to recruit the MRN complex ${ }^{138}$; part of the DNA damage response pathway which is upregulated in HD. Increased p53 levels in HD promotes $\mathrm{mHTT}$ 
aggregation and UBR5 can upregulate p53 ubiquitin-independently by inhibiting ATM-mediated phosphorylation ${ }^{139}$. As UBR5 plays such a central multi-faceted role in HD phenotype, targeting its activity for inhibition with small molecules seems an obvious therapeutic avenue to be explored (Figure 3).

\section{Considerations and Limitations of studying and targeting these pathways in current} studies

Elevating protein degradation rates by targeting autophagy and UPS activation has significant therapeutic potential in a range of neurodegenerative proteinopathies, including HD. However, it should be noted that clinical trials in HD have extremely low rates of success ${ }^{140}$ with many promising therapies failing to translate from the laboratory to the clinic. This is largely attributed to poor understanding of the basic biology of HD, for example, the function of HTT either wildtype or polyQ expanded and the central focus disease research, is still largely unknown. Additionally, concerns about the disease models used to identify therapeutic targets and evaluate drug efficacy in preclinical research often have critical flaws or caveats in their representation of HD patient neurophysiology and disease progression. Thus, when considering potential avenues for future therapeutic development, it is important to carefully evaluate the published findings.

A key issue with many of the therapeutic reagents described within this review is that these are molecules which have undefined in vitro and in vivo potency and selectivity for their target proteins nor precisely defined mechanisms of action. Whilst promising phenotypes may be observed in disease models following a particular treatment, target engagement is often not validated, meaning that phenotypic changes observed may be due to polypharmacology; a combination of on- and off- target effects resulting from modulation of both target and peripheral pathways ${ }^{141}$. Molecules such as rapamycin, which is reported to be both potent and selective, has been observed to have $\mathrm{IC}_{50}$ values for 
mTORC1 which may range over many orders of magnitude dependent on the cell line or model being used and long term low dose rapamycin treatment has also been observed to additionally antagonise mTORC2 ${ }^{142,143}$. Therefore, therapeutic dose concentration and regimen should be carefully considered and evaluated to ensure that phenotypes observed from treatments are due to validated selective target engagement. Ideally, high quality chemical probes for each of the protein targets in question should be used to ensure treatment responses are due to on target effects, are dose-dependent and have a defined mechanism of action ${ }^{144-146}$. The range of commercially available high quality chemical probes is expanding and information regarding potency and selectively can easily be retrieved through resources such as the chemical probes portal http://www.chemicalprobes.org.

It is increasingly realized that target identification and validation are critical for the success of targetbased drug discovery of oncology $y^{147}$ and neurological disorders ${ }^{148}$. In the case that high quality chemical tools are not available, we and our collaborative labs have developed highly specific and potent proteinaceous biological binder, ubiquitin variants, to interfere with the ubiquitin regulatory enzymes $^{149,150}$ for target validation purpose. Use of such tool molecules will help identify and validate therapeutic targets in the HTT proteostatis pathway.

Given the progressive and age-dependent nature of HD symptoms, the time-point of targeting HTT with lowering therapies, either via UPS or autophagy upregulation, will likely be critical for the efficacy of any developed treatment. The preference for degradation of smaller, more soluble misfolded ubiquitinated proteins or aggregates by the UPS will mean that later time-points of disease progression will likely show minimal improvement with treatments targeting this pathway ${ }^{151}$. This is exemplified in the ability of rapamycin to ameliorate cognitive deficits in mouse models of Alzheimer's but only when treatment was given prior to the formation of plaques and tangles of the amyloid-beta protein $^{125}$. To determine whether autophagy or UPS should be targeted for HTT clearance, it will be critical to analyse 
the pathway preference for different HTT aggregate species, ideally from studies using tissue relevant patient derived cells, throughout the progression of HD neurodegeneration. Additionally, in considerations of treatment regimen, it is probable that continuously switching on the protein degradation pathways is likely to yield deleterious effects in the cell due to the degradation of off target substrates. It has been suggested that a pulsatile treatment regimen, likened to periodically removing the rubbish ${ }^{117}$, would be an effective strategy to allow maximal drug efficacy with reduced toxicity.

The HD models used in each of the studies detailed in this review, report data on HTT clearance from models which can be quite disparate. Some studies are limited to data collected in vitro, using cultured cells, whereas others see effects in vivo, which, in general, use mouse models. Which form of $\mathrm{mHTT}$ is overexpressed in these different models also varies. For example, the commonly used R6/2 HD mice express human HTT exon1 with approximately 150 CAG repeats $^{153}$, which, whilst sufficient to cause progressive neurodegenerative phenotypes in the mice in question, does not represent the same genetic insult characterised in patients and therefore is unlikely to lead to the same trajectory in disease progression in HD patients. Clearance of HTT aggregates formed solely of HTT exon1 Q150 is not representative of the situation in HD patients which have a smaller polyQ expansion and a heterogeneous mix of aggregate species. Whilst modulation of HTT clearance in the R6/2 mouse model may give indications of possible therapeutic strategies, observations should be made cautiously and ideally verified in alternative disease models and systems. Although other mouse models, such as YAC128 and BACHD do express full-length human HTT, which is $91 \%$ sequence identical to the mouse protein, and show progressive late-onset neurodegenerative symptoms, both use polyQ expansions in excess of 100 glutamines which is not representative of the HTT protein expressed in most HD patients ${ }^{154,155}$. Longer CAG expansions give more robust phenotypes in animal models and longer polyQ expansions permits easier detection of $\mathrm{mHTT}$ compared to wildtype so larger CAG expansions have historically been preferred for study. However, as polyQ stretches might clog the UPS machinery and are 
regarded as the principal factor in HTT aggregate formation, expression of exaggerated polyQ-length HTT proteins may give rise to different phenotypes when observing the HTT clearance pathways and their modulation by therapeutics compared to the situation in HD patients. Whilst the monogenic nature of HD should simplify the generation of an accurate and disease representative mouse model, it is important to note that the discovery of therapeutics with efficacy in mouse models of HD has yet to translate to success in the clinic. Whilst this is a multi-factorial problem, it does suggest that there are critical differences in neurophysiology, neurodegeneration and ageing between rodents and humans which are deserving of further investigation ${ }^{140}$.

In recent years, HD patient-derived cell lines are more routinely used for in vitro experiments and are available from data and cell repositories such as the National Institute of Neurological Disorders and Stroke (NINDS) which currently hosts 27 HD patient fibroblast cell lines and 23 HD patient induced pluripotent stem cell lines (iPSCs). This collection encompasses samples from both male and female subjects of ages 9-87 representing both control and HD patient samples. HTT gene CAG lengths represented include controls of Q17 to Q29 and HD patient samples spanning Q38 to Q180 although most are Q40 to Q50. The most commonly studied HD iPSC line to date has 60 CAG repeats putting it at the very high end of HD adult onset CAG expansions ${ }^{156}$. Despite cell lines with more representative repeats for adult onset HD being described, iPSCs with CAG repeats ranging from 43-60 CAGs, they are less extensively characterised. Perhaps similarly to animal models, this is due to the more robust phenotypes with larger CAG repeat expansions and the greater ease for detecting $\mathrm{mHTT}$.

A number of protocols can be used to differentiate iPSCs into cells exhibiting neuronal features, often referred to as neural precursor cells (NPCs). The variety of methods of differentiation as well as the genetic background of each NPC line gives rise to different disease-associated phenotypes ${ }^{157}$ so findings derived from study in one NPC line should be viewed cautiously and a field-wide consensus on a 
restricted number of phenotypes would improve comparative studies. Ideal experiments would also ensure a selection of NPCs derived from different HD patients as well as controls are differentiated by the same methods and tested in parallel to verify findings although this approach would be resource and time expensive. To date, limited work has been published on mHTT clearance in iPSC derived cells. One study showed that microRNA-196a is able to decrease levels of HTT aggregate in neuronal cultures differentiated from HD iPSCs but the mechanism of action for this observed effect is unknown ${ }^{158}$. Replicating the findings of therapeutics detailed in this review in iPSCs would build confidence that such strategies are deserving of further development as HTT lowering therapies. One key caveat of HD iPSC derived cells for studying HD is that induced pluripotency is reported to reverse age-related phenotypes of the patient sample which could prove problematic given the progressive and age-dependent nature of HD. None-the-less, a mHTT aggregation and clearance study in HD iPSCs with adult-onset polyQ expansions would be helpful to verify and characterise the pathways to target for therapeutic development which are relevant to HD patients.

Whilst there are obvious commonalities between different neurodegenerative proteinopathies, transfer of knowledge between different diseases should be done cautiously. For example, in the case of rapamycin treatment, HD transgenic mice show improved motor behaviours ${ }^{159}$ and similarly encouraging results are seen in Alzheimer's $\mathrm{s}^{152}$ and Parkinson's $\mathrm{s}^{160}$ models of disease. However, rapamycin treatment in an ALS SOD1 transgenic mouse model ${ }^{161}$ actually worsens autophagic functions and exacerbates the neurodegenerative phenotype. As such, extrapolation of findings from different diseases, or even different models of the same disease, should be done so prudently.

Whilst some therapeutics described in this review are still under active investigation as exemplified by frequent and continuing publication of new findings, some approaches show large gaps or halts in the published literature. This suggests that perhaps findings could not be replicated by other groups or in 
other HD models studied with negative results not reaching traditional published literature outlets due to publication bias ${ }^{162}$. Therefore, the validity of certain therapeutics suggested in limited numbers of studies should be analysed and evaluated cautiously.

\section{Conclusions}

Alleviating symptoms of Huntington's disease through HTT lowering therapies remains an attractive avenue for therapeutic development and a major focus area for many HD researchers. In the absence of a complete understanding for the biological function of wildtype HTT, nor consensus on the gain-offunction phenotype described for expressed $\mathrm{mHTT}$, eradicating $\mathrm{mHTT}$ from the affected tissues in HD patients remains a rational drug discovery strategy.

The monogenic nature of HD makes it an attractive candidate for therapies which might target transcription or translation of the mutant allele ${ }^{87}$. Current strategies in development include including antisense oligonucleotides and RNA interference targeting of mRNA, zinc-finger transcriptional repressors of gene expression as well as more recently CRISPR-Cas9. Whilst these efforts are very promising, the resultant therapies from these approaches will likely be prohibitively expensive for many $\mathrm{HD}$ patients and currently suffer from issues of effective blood brain barrier penetration via oral or subcutaneous delivery. Although small molecule based approaches such as those detailed in this review, may also suffer from these attributes, the possibility to develop brain penetrant drugs which may be more easily scaled for production is probably more achievable, making these approaches attractive still.

Recent advances permitting researchers greater access to HD patient derived cell lines should allow better scrutiny of therapeutics in disease relevant tissues prior to advancing in preclinical development. GWAS of HD patients have given insight into possible new targets for drug discovery and the recently highlighted UBR5 is one such example of an attractive candidate for inhibition given its multi-faceted role in HD. Developments in PROTAC-based approaches for drug design are making headway in other 
fields ${ }^{131,132}$ and represent a new avenue for researchers to explore for HTT lowering therapies. Despites its monogenic inheritance, intensive research into HD in the previous few decades has shown that HD is far from a simple pathology and it is probable that effective disease-modifying therapies are unlikely to be developed in the near future given the complexity of this neurodegenerative disease and our current limited understanding of the biology. However, with respect to HTT lowering therapies targeting the HTT protein itself, the recent advances described in this review should be cause for optimism in their ability to assist researchers in effective, productive and rational drug discovery.

\section{Acknowledgements}

The SGC is a registered charity (number 1097737) that receives funds from AbbVie, Bayer Pharma AG, Boehringer Ingelheim, Canada Foundation for Innovation, Eshelman Institute for Innovation, Genome Canada through Ontario Genomics Institute, Innovative Medicines Initiative (EU/EFPIA) [ULTRADD grant no. 115766], Janssen, Merck \& Co., Novartis Pharma AG, Ontario Ministry of Economic Development and Innovation, Pfizer, São Paulo Research Foundation-FAPESP, Takeda, and the Wellcome Trust. Additional funding from the Collaborative Research and Training Experience grant (Aled Edwards 432008-2013) from the Natural Sciences and Engineering Research Council of Canada. We thank Diamond Light Source for access to beamline i04-1 and the XChem facility that contributed to the results within this manuscript.

\section{References:}

(1) Vonsattel, J. P.; DiFiglia, M. Huntington Disease. J. Neuropathol. Exp. Neurol. 1998, 57 (5), 369384.

(2) Kay, C.; Hayden, M. R.; Leavitt, B. R. Chapter 3 - Epidemiology of Huntington Disease. In Handbook of Clinical Neurology; Feigin, A. S., Anderson, K. E., Eds.; Huntington Disease; Elsevier, 2017; Vol. 144, pp 31-46.

(3) Ross, C. A.; Aylward, E. H.; Wild, E. J.; Langbehn, D. R.; Long, J. D.; Warner, J. H.; Scahill, R. I.; Leavitt, B. R.; Stout, J. C.; Paulsen, J. S.; Reilmann, R.; Unschuld, P. G.; Wexler, A.; Margolis, R. L.; Tabrizi, S. J. Huntington Disease: Natural History, Biomarkers and Prospects for Therapeutics. Nat. Rev. Neurol. 2014, 10 (4), 204-216. 
(4) A Novel Gene Containing a Trinucleotide Repeat That Is Expanded and Unstable on Huntington's Disease Chromosomes. The Huntington's Disease Collaborative Research Group. Cell 1993, 72 (6), 971-983.

(5) Kay, C., Fisher, E. R. \& Hayden, M. R. Huntington's Disease Chapter 7 (Eds Bates, G. P., Tabrizi, S. J. \& Jones, L.), 4th ed.; Oxford University Press, 2014.

(6) Semaka, A.; Kay, C.; Doty, C.; Collins, J. A.; Bijlsma, E. K.; Richards, F.; Goldberg, Y. P.; Hayden, M. R. CAG Size-Specific Risk Estimates for Intermediate Allele Repeat Instability in Huntington Disease. J. Med. Genet. 2013, 50 (10), 696-703.

(7) Lee, J.-M.; Ramos, E. M.; Lee, J.-H.; Gillis, T.; Mysore, J. S.; Hayden, M. R.; Warby, S. C.; Morrison, P.; Nance, M.; Ross, C. A.; Margolis, R. L.; Squitieri, F.; Orobello, S.; Di Donato, S.; GomezTortosa, E.; Ayuso, C.; Suchowersky, O.; Trent, R. J. A.; McCusker, E.; Novelletto, A.; Frontali, M.; Jones, R.; Ashizawa, T.; Frank, S.; Saint-Hilaire, M. H.; Hersch, S. M.; Rosas, H. D.; Lucente, D.; Harrison, M. B.; Zanko, A.; Abramson, R. K.; Marder, K.; Sequeiros, J.; Paulsen, J. S.; PREDICT-HD study of the Huntington Study Group (HSG); Landwehrmeyer, G. B.; REGISTRY study of the European Huntington's Disease Network; Myers, R. H.; HD-MAPS Study Group; MacDonald, M. E.; Gusella, J. F.; COHORT study of the HSG. CAG Repeat Expansion in Huntington Disease Determines Age at Onset in a Fully Dominant Fashion. Neurology 2012, 78 (10), 690-695.

(8) Kim, M.; Lee, H. S.; LaForet, G.; McIntyre, C.; Martin, E. J.; Chang, P.; Kim, T. W.; Williams, M.; Reddy, P. H.; Tagle, D.; Boyce, F. M.; Won, L.; Heller, A.; Aronin, N.; Difiglia, M. Mutant Huntingtin Expression in Clonal Striatal Cells: Dissociation of Inclusion Formation and Neuronal Survival by Caspase Inhibition. J. Neurosci. Off. J. Soc. Neurosci. 1999, 19 (3), 964-973.

(9) Seredenina, T.; Luthi-Carter, R. What Have We Learned from Gene Expression Profiles in Huntington's Disease? Neurobiol. Dis. 2012, 45 (1), 83-98.

(10) Johri, A.; Chandra, A.; Beal, M. F. PGC-1 $\alpha$, Mitochondrial Dysfunction, and Huntington's Disease. Free Radic. Biol. Med. 2013, 62, 37-46.

(11) Reddy, P. H.; Shirendeb, U. P. Mutant Huntingtin, Abnormal Mitochondrial Dynamics, Defective Axonal Transport of Mitochondria, and Selective Synaptic Degeneration in Huntington's Disease. Biochim. Biophys. Acta 2012, 1822 (2), 101-110.

(12) Ju, T.-C.; Lin, Y.-S.; Chern, Y. Energy Dysfunction in Huntington's Disease: Insights from PGC-1 $\alpha$, AMPK, and CKB. Cell. Mol. Life Sci. CMLS 2012, 69 (24), 4107-4120.

(13) Nithianantharajah, J.; Hannan, A. J. Dysregulation of Synaptic Proteins, Dendritic Spine Abnormalities and Pathological Plasticity of Synapses as Experience-Dependent Mediators of Cognitive and Psychiatric Symptoms in Huntington's Disease. Neuroscience 2013, 251, 66-74.

(14) Franciosi, S.; Shim, Y.; Lau, M.; Hayden, M. R.; Leavitt, B. R. A Systematic Review and MetaAnalysis of Clinical Variables Used in Huntington Disease Research. Mov. Disord. Off. J. Mov. Disord. Soc. 2013, 28 (14), 1987-1994.

(15) Andrade, M. A.; Petosa, C.; O'Donoghue, S. I.; Müller, C. W.; Bork, P. Comparison of ARM and HEAT Protein Repeats. J. Mol. Biol. 2001, 309 (1), 1-18.

(16) Saudou, F.; Humbert, S. The Biology of Huntingtin. Neuron 2016, 89 (5), 910-926.

(17) Ratovitski, T.; O'Meally, R. N.; Jiang, M.; Chaerkady, R.; Chighladze, E.; Stewart, J. C.; Wang, X.; Arbez, N.; Roby, E.; Alexandris, A.; Duan, W.; Vijayvargia, R.; Seong, I. S.; Lavery, D. J.; Cole, R. N.; Ross, C. A. Post-Translational Modifications (PTMs), Identified on Endogenous Huntingtin, Cluster within Proteolytic Domains between HEAT Repeats. J. Proteome Res. 2017.

(18) DiGiovanni, L. F.; Mocle, A. J.; Xia, J.; Truant, R. Huntingtin N17 Domain Is a Reactive Oxygen Species Sensor Regulating Huntingtin Phosphorylation and Localization. Hum. Mol. Genet. 2016, 25 (18), 3937-3945. 
(19) Arrasate, M.; Mitra, S.; Schweitzer, E. S.; Segal, M. R.; Finkbeiner, S. Inclusion Body Formation Reduces Levels of Mutant Huntingtin and the Risk of Neuronal Death. Nature 2004, 431 (7010), 805-810.

(20) Davies, S. W.; Turmaine, M.; Cozens, B. A.; DiFiglia, M.; Sharp, A. H.; Ross, C. A.; Scherzinger, E.; Wanker, E. E.; Mangiarini, L.; Bates, G. P. Formation of Neuronal Intranuclear Inclusions Underlies the Neurological Dysfunction in Mice Transgenic for the HD Mutation. Cell 1997, 90 (3), 537-548.

(21) Difiglia, M.; Sapp, E.; Chase, K. O.; Davies, S. W.; Bates, G. P.; Vonsattel, J. P.; Aronin, N. Aggregation of Huntingtin in Neuronal Intranuclear Inclusions and Dystrophic Neurites in Brain. Science 1997, 277 (5334), 1990-1993.

(22) Gutekunst, C.-A.; Li, S.-H.; Yi, H.; Mulroy, J. S.; Kuemmerle, S.; Jones, R.; Rye, D.; Ferrante, R. J.; Hersch, S. M.; Li, X.-J. Nuclear and Neuropil Aggregates in Huntington's Disease: Relationship to Neuropathology. J. Neurosci. 1999, 19 (7), 2522-2534.

(23) Scherzinger, E.; Lurz, R.; Turmaine, M.; Mangiarini, L.; Hollenbach, B.; Hasenbank, R.; Bates, G. P.; Davies, S. W.; Lehrach, H.; Wanker, E. E. Huntingtin-Encoded Polyglutamine Expansions Form Amyloid-like Protein Aggregates in Vitro and in Vivo. Cell 1997, 90 (3), 549-558.

(24) Chen, S.; Berthelier, V.; Yang, W.; Wetzel, R. Polyglutamine Aggregation Behavior in Vitro Supports a Recruitment Mechanism of Cytotoxicity. J. Mol. Biol. 2001, 311 (1), 173-182.

(25) Morley, J. F.; Brignull, H. R.; Weyers, J. J.; Morimoto, R. I. The Threshold for PolyglutamineExpansion Protein Aggregation and Cellular Toxicity Is Dynamic and Influenced by Aging in Caenorhabditis Elegans. Proc. Natl. Acad. Sci. U. S. A. 2002, 99 (16), 10417-10422.

(26) Vijayvargia, R.; Epand, R.; Leitner, A.; Jung, T.-Y.; Shin, B.; Jung, R.; Lloret, A.; Singh Atwal, R.; Lee, H.; Lee, J.-M.; Aebersold, R.; Hebert, H.; Song, J.-J.; Seong, I. S. Huntingtin's Spherical Solenoid Structure Enables Polyglutamine Tract-Dependent Modulation of Its Structure and Function. elife 2016, 5, e11184.

(27) Harding, R.; Deme, J.; Loppnau, P.; Ackloo, S.; Hutchinson, A.; Hunt, B.; Seitova, A.; Lea, S.; Arrowsmith, C. H.; Edwards, A. M.; Holehouse, A. S. Pursuit of a High Resolution Structure of Full-Length Huntingtin by Cryo-Electron Microscopy: CHDI HD Therapeutics Conference 2017; 2017.

(28) Zheng, Z.; Diamond, M. I. Huntington Disease and the Huntingtin Protein. Prog. Mol. Biol. Transl. Sci. 2012, 107, 189-214.

(29) Rui, Y.-N.; Xu, Z.; Patel, B.; Chen, Z.; Chen, D.; Tito, A.; David, G.; Sun, Y.; Stimming, E. F.; Bellen, H. J.; Cuervo, A. M.; Zhang, S. Huntingtin Functions as a Scaffold for Selective Macroautophagy. Nat. Cell Biol. 2015, 17 (3), 262-275.

(30) Kalathur, R. K. R.; Pinto, J. P.; Sahoo, B.; Chaurasia, G.; Futschik, M. E. HDNetDB: A Molecular Interaction Database for Network-Oriented Investigations into Huntington's Disease. Sci. Rep. 2017, 7 (1), 5216.

(31) Giorgini, F. A Flexible Polyglutamine Hinge Opens New Doors for Understanding Huntingtin Function. Proc. Natl. Acad. Sci. U. S. A. 2013, 110 (36), 14516-14517.

(32) Trepte, P.; Strempel, N.; Wanker, E. E. Spontaneous Self-Assembly of Pathogenic Huntingtin Exon 1 Protein into Amyloid Structures. Essays Biochem. 2014, 56, 167-180.

(33) Thakur, A. K.; Jayaraman, M.; Mishra, R.; Thakur, M.; Chellgren, V. M.; Byeon, I.-J.; Anjum, D. H.; Kodali, R.; Creamer, T. P.; Conway, J. F.; M.Gronenborn, A.; Wetzel, R. Polyglutamine Disruption of the Huntingtin exon1 N-Terminus Triggers a Complex Aggregation Mechanism. Nat. Struct. Mol. Biol. 2009, 16 (4), 380-389.

(34) Chen, M.; Wolynes, P. G. Aggregation Landscapes of Huntingtin Exon 1 Protein Fragments and the Critical Repeat Length for the Onset of Huntington's Disease. Proc. Natl. Acad. Sci. 2017, 114 (17), 4406-4411. 
(35) Pieri, L.; Madiona, K.; Bousset, L.; Melki, R. Fibrillar $\alpha$-Synuclein and Huntingtin Exon 1 Assemblies Are Toxic to the Cells. Biophys. J. 2012, 102 (12), 2894-2905.

(36) Mangiarini, L.; Sathasivam, K.; Seller, M.; Cozens, B.; Harper, A.; Hetherington, C.; Lawton, M.; Trottier, Y.; Lehrach, H.; Davies, S. W.; Bates, G. P. Exon 1 of the HD Gene with an Expanded CAG Repeat Is Sufficient to Cause a Progressive Neurological Phenotype in Transgenic Mice. Cell 1996, 87 (3), 493-506.

(37) Daldin, M.; Fodale, V.; Cariulo, C.; Azzollini, L.; Verani, M.; Martufi, P.; Spiezia, M. C.; Deguire, S. M.; Cherubini, M.; Macdonald, D.; Weiss, A.; Bresciani, A.; Vonsattel, J.-P. G.; Petricca, L.; Marsh, J. L.; Gines, S.; Santimone, I.; Marano, M.; Lashuel, H. A.; Squitieri, F.; Caricasole, A. Polyglutamine Expansion Affects Huntingtin Conformation in Multiple Huntington's Disease Models. Sci. Rep. 2017, 7 (1), 5070.

(38) Atwal, R. S.; Desmond, C. R.; Caron, N.; Maiuri, T.; Xia, J.; Sipione, S.; Truant, R. Kinase Inhibitors Modulate Huntingtin Cell Localization and Toxicity. Nat. Chem. Biol. 2011, 7 (7), 453-460.

(39) Yerbury, J. J.; Ooi, L.; Dillin, A.; Saunders, D. N.; Hatters, D. M.; Beart, P. M.; Cashman, N. R.; Wilson, M. R.; Ecroyd, H. Walking the Tightrope: Proteostasis and Neurodegenerative Disease. J. Neurochem. 2016, 137 (4), 489-505.

(40) Li, W.; Ye, Y. Polyubiquitin Chains: Functions, Structures, and Mechanisms. Cell. Mol. Life Sci. CMLS 2008, 65 (15), 2397-2406.

(41) Lin, L.; Jin, Z.; Tan, H.; Xu, Q.; Peng, T.; Li, H. Atypical Ubiquitination by E3 Ligase WWP1 Inhibits the Proteasome-Mediated Degradation of Mutant Huntingtin. Brain Res. 2016, 1643, 103-112.

(42) Bhat, K. P.; Yan, S.; Wang, C.-E.; Li, S.; Li, X.-J. Differential Ubiquitination and Degradation of Huntingtin Fragments Modulated by Ubiquitin-Protein Ligase E3A. Proc. Natl. Acad. Sci. 2014, 111 (15), 5706-5711.

(43) Rotblat, B.; Southwell, A. L.; Ehrnhoefer, D. E.; Skotte, N. H.; Metzler, M.; Franciosi, S.; Leprivier, G.; Somasekharan, S. P.; Barokas, A.; Deng, Y.; Tang, T.; Mathers, J.; Cetinbas, N.; Daugaard, M.; Kwok, B.; Li, L.; Carnie, C. J.; Fink, D.; Nitsch, R.; Galpin, J. D.; Ahern, C. A.; Melino, G.; Penninger, J. M.; Hayden, M. R.; Sorensen, P. H. HACE1 Reduces Oxidative Stress and Mutant Huntingtin Toxicity by Promoting the NRF2 Response. Proc. Natl. Acad. Sci. U. S. A. 2014, 111 (8), 30323037.

(44) Al-Ramahi, I.; Lam, Y. C.; Chen, H.-K.; de Gouyon, B.; Zhang, M.; Pérez, A. M.; Branco, J.; de Haro, M.; Patterson, C.; Zoghbi, H. Y.; Botas, J. CHIP Protects from the Neurotoxicity of Expanded and Wild-Type Ataxin-1 and Promotes Their Ubiquitination and Degradation. J. Biol. Chem. 2006, 281 (36), 26714-26724.

(45) Jana, N. R.; Dikshit, P.; Goswami, A.; Kotliarova, S.; Murata, S.; Tanaka, K.; Nukina, N. CoChaperone CHIP Associates with Expanded Polyglutamine Protein and Promotes Their Degradation by Proteasomes. J. Biol. Chem. 2005, 280 (12), 11635-11640.

(46) Yang, H.; Zhong, X.; Ballar, P.; Luo, S.; Shen, Y.; Rubinsztein, D. C.; Monteiro, M. J.; Fang, S. Ubiquitin Ligase Hrd1 Enhances the Degradation and Suppresses the Toxicity of PolyglutamineExpanded Huntingtin. Exp. Cell Res. 2007, 313 (3), 538-550.

(47) Rubio, I.; Rodríguez-Navarro, J. A.; Tomás-Zapico, C.; Ruíz, C.; Casarejos, M. J.; Perucho, J.; Gómez, A.; Rodal, I.; Lucas, J. J.; Mena, M. A.; de Yébenes, J. G. Effects of Partial Suppression of Parkin on Huntingtin Mutant R6/1 Mice. Brain Res. 2009, 1281, 91-100.

(48) Yang, J.; Hao, X.; Cao, X.; Liu, B.; Nyström, T. Spatial Sequestration and Detoxification of Huntingtin by the Ribosome Quality Control Complex. eLife 2016, 5.

(49) Komander, D.; Rape, M. The Ubiquitin Code. Annu. Rev. Biochem. 2012, 81, 203-229.

(50) Tsou, W.-L.; Ouyang, M.; Hosking, R. R.; Sutton, J. R.; Blount, J. R.; Burr, A. A.; Todi, S. V. The Deubiquitinase Ataxin-3 Requires Rad23 and DnaJ-1 for Its Neuroprotective Role in Drosophila Melanogaster. Neurobiol. Dis. 2015, 82, 12-21. 
(51) Eckland, D. J.; Lightman, S. L. The TSH, T4, T3 and Prolactin Responses to Consecutive Infusions of a Potent and Stabilized Thyrotrophin Releasing Hormone Analogue, RX77368, in Man. Eur. J. Clin. Invest. 1988, 18 (4), 405-409.

(52) Ochaba, J.; Monteys, A. M.; O’Rourke, J. G.; Reidling, J. C.; Steffan, J. S.; Davidson, B. L.; Thompson, L. M. PIAS1 Regulates Mutant Huntingtin Accumulation and Huntington's DiseaseAssociated Phenotypes In Vivo. Neuron 2016, 90 (3), 507-520.

(53) Livneh, I.; Kravtsova-Ivantsiv, Y.; Braten, O.; Kwon, Y. T.; Ciechanover, A. Monoubiquitination Joins Polyubiquitination as an Esteemed Proteasomal Targeting Signal. BioEssays News Rev. Mol. Cell. Dev. Biol. 2017, 39 (6).

(54) Waelter, S.; Boeddrich, A.; Lurz, R.; Scherzinger, E.; Lueder, G.; Lehrach, H.; Wanker, E. E. Accumulation of Mutant Huntingtin Fragments in Aggresome-like Inclusion Bodies as a Result of Insufficient Protein Degradation. Mol. Biol. Cell 2001, 12 (5), 1393-1407.

(55) Wang, J.; Wang, C.-E.; Orr, A.; Tydlacka, S.; Li, S.-H.; Li, X.-J. Impaired Ubiquitin-proteasome System Activity in the Synapses of Huntington's Disease Mice. J. Cell Biol. 2008, 180 (6), 11771189.

(56) Li, X.-J.; Li, S. Proteasomal Dysfunction in Aging and Huntington Disease. Neurobiol. Dis. 2011, 43 (1), 4-8.

(57) Konstantinova, I. M.; Tsimokha, A. S.; Mittenberg, A. G. Role of Proteasomes in Cellular Regulation. In International Review of Cell and Molecular Biology; Academic Press, 2008; Vol. 267, pp 59-124.

(58) Díaz-Hernández, M.; Valera, A. G.; Morán, M. A.; Gómez-Ramos, P.; Alvarez-Castelao, B.; Castaño, J. G.; Hernández, F.; Lucas, J. J. Inhibition of 265 Proteasome Activity by Huntingtin Filaments but Not Inclusion Bodies Isolated from Mouse and Human Brain. J. Neurochem. 2006, 98 (5), 1585-1596.

(59) Schipper-Krom, S.; Juenemann, K.; Jansen, A. H.; Wiemhoefer, A.; van den Nieuwendijk, R.; Smith, D. L.; Hink, M. A.; Bates, G. P.; Overkleeft, H.; Ovaa, H.; Reits, E. Dynamic Recruitment of Active Proteasomes into Polyglutamine Initiated Inclusion Bodies. FEBS Lett. 2014, 588 (1), 151-159.

(60) Bennett, E. J.; Bence, N. F.; Jayakumar, R.; Kopito, R. R. Global Impairment of the UbiquitinProteasome System by Nuclear or Cytoplasmic Protein Aggregates Precedes Inclusion Body Formation. Mol. Cell 2005, 17 (3), 351-365.

(61) Holmberg, C. I.; Staniszewski, K. E.; Mensah, K. N.; Matouschek, A.; Morimoto, R. I. Inefficient Degradation of Truncated Polyglutamine Proteins by the Proteasome. EMBO J. 2004, 23 (21), 4307-4318.

(62) Venkatraman, P.; Wetzel, R.; Tanaka, M.; Nukina, N.; Goldberg, A. L. Eukaryotic Proteasomes Cannot Digest Polyglutamine Sequences and Release Them during Degradation of Polyglutamine-Containing Proteins. Mol. Cell 2004, 14 (1), 95-104.

(63) Michalik, A.; Van Broeckhoven, C. Proteasome Degrades Soluble Expanded Polyglutamine Completely and Efficiently. Neurobiol. Dis. 2004, 16 (1), 202-211.

(64) Juenemann, K.; Schipper-Krom, S.; Wiemhoefer, A.; Kloss, A.; Sanz Sanz, A.; Reits, E. A. J. Expanded Polyglutamine-Containing N-Terminal Huntingtin Fragments Are Entirely Degraded by Mammalian Proteasomes. J. Biol. Chem. 2013, 288 (38), 27068-27084.

(65) Maheshwari, M.; Samanta, A.; Godavarthi, S. K.; Mukherjee, R.; Jana, N. R. Dysfunction of the Ubiquitin Ligase Ube3a May Be Associated with Synaptic Pathophysiology in a Mouse Model of Huntington Disease. J. Biol. Chem. 2012, 287 (35), 29949-29957.

(66) Grice, G. L.; Nathan, J. A. The Recognition of Ubiquitinated Proteins by the Proteasome. Cell. Mol. Life Sci. CMLS 2016, 73 (18), 3497-3506. 
(67) Martinez-Vicente, M.; Talloczy, Z.; Wong, E.; Tang, G.; Koga, H.; Kaushik, S.; de Vries, R.; Arias, E.; Harris, S.; Sulzer, D.; Cuervo, A. M. Cargo Recognition Failure Is Responsible for Inefficient Autophagy in Huntington's Disease. Nat. Neurosci. 2010, 13 (5), 567-576.

(68) Wong, Y. C.; Holzbaur, E. L. F. The Regulation of Autophagosome Dynamics by Huntingtin and HAP1 Is Disrupted by Expression of Mutant Huntingtin, Leading to Defective Cargo Degradation. J. Neurosci. Off. J. Soc. Neurosci. 2014, 34 (4), 1293-1305.

(69) Mealer, R. G.; Murray, A. J.; Shahani, N.; Subramaniam, S.; Snyder, S. H. Rhes, a Striatal-Selective Protein Implicated in Huntington Disease, Binds Beclin-1 and Activates Autophagy. J. Biol. Chem. 2014, 289 (6), 3547-3554.

(70) Ravikumar, B.; Vacher, C.; Berger, Z.; Davies, J. E.; Luo, S.; Oroz, L. G.; Scaravilli, F.; Easton, D. F.; Duden, R.; O'Kane, C. J.; Rubinsztein, D. C. Inhibition of mTOR Induces Autophagy and Reduces Toxicity of Polyglutamine Expansions in Fly and Mouse Models of Huntington Disease. Nat. Genet. 2004, 36 (6), 585-595.

(71) Kim, J.; Kundu, M.; Viollet, B.; Guan, K.-L. AMPK and mTOR Regulate Autophagy through Direct Phosphorylation of Ulk1. Nat. Cell Biol. 2011, 13 (2), 132-141.

(72) Rubinsztein, D. C. Autophagy Induction Rescues Toxicity Mediated by Proteasome Inhibition. Neuron 2007, 54 (6), 854-856.

(73) Pandey, U. B.; Nie, Z.; Batlevi, Y.; McCray, B. A.; Ritson, G. P.; Nedelsky, N. B.; Schwartz, S. L.; DiProspero, N. A.; Knight, M. A.; Schuldiner, O.; Padmanabhan, R.; Hild, M.; Berry, D. L.; Garza, D.; Hubbert, C. C.; Yao, T.-P.; Baehrecke, E. H.; Taylor, J. P. HDAC6 Rescues Neurodegeneration and Provides an Essential Link between Autophagy and the UPS. Nature 2007, 447 (7146), 859863.

(74) Lackie, R. E.; Maciejewski, A.; Ostapchenko, V. G.; Marques-Lopes, J.; Choy, W.-Y.; Duennwald, M. L.; Prado, V. F.; Prado, M. A. M. The Hsp70/Hsp90 Chaperone Machinery in Neurodegenerative Diseases. Front. Neurosci. 2017, 11, 254.

(75) Baldo, B.; Weiss, A.; Parker, C. N.; Bibel, M.; Paganetti, P.; Kaupmann, K. A Screen for Enhancers of Clearance Identifies Huntingtin as a Heat Shock Protein 90 (Hsp90) Client Protein. J. Biol. Chem. 2012, 287 (2), 1406-1414.

(76) Jana, N. R.; Tanaka, M.; Wang, G. h; Nukina, N. Polyglutamine Length-Dependent Interaction of Hsp40 and Hsp70 Family Chaperones with Truncated N-Terminal Huntingtin: Their Role in Suppression of Aggregation and Cellular Toxicity. Hum. Mol. Genet. 2000, 9 (13), 2009-2018.

(77) Hay, D. G.; Sathasivam, K.; Tobaben, S.; Stahl, B.; Marber, M.; Mestril, R.; Mahal, A.; Smith, D. L.; Woodman, B.; Bates, G. P. Progressive Decrease in Chaperone Protein Levels in a Mouse Model of Huntington's Disease and Induction of Stress Proteins as a Therapeutic Approach. Hum. Mol. Genet. 2004, 13 (13), 1389-1405.

(78) Sittler, A.; Lurz, R.; Lueder, G.; Priller, J.; Lehrach, H.; Hayer-Hartl, M. K.; Hartl, F. U.; Wanker, E. E. Geldanamycin Activates a Heat Shock Response and Inhibits Huntingtin Aggregation in a Cell Culture Model of Huntington's Disease. Hum. Mol. Genet. 2001, 10 (12), 1307-1315.

(79) Muchowski, P. J.; Schaffar, G.; Sittler, A.; Wanker, E. E.; Hayer-Hartl, M. K.; Hartl, F. U. Hsp70 and hsp40 Chaperones Can Inhibit Self-Assembly of Polyglutamine Proteins into Amyloid-like Fibrils. Proc. Natl. Acad. Sci. U. S. A. 2000, 97 (14), 7841-7846.

(80) Wacker, J. L.; Huang, S.-Y.; Steele, A. D.; Aron, R.; Lotz, G. P.; Nguyen, Q.; Giorgini, F.; Roberson, E. D.; Lindquist, S.; Masliah, E.; Muchowski, P. J. Loss of Hsp70 Exacerbates Pathogenesis but Not Levels of Fibrillar Aggregates in a Mouse Model of Huntington's Disease. J. Neurosci. Off. J. Soc. Neurosci. 2009, 29 (28), 9104-9114.

(81) Tsai, Y. C.; Fishman, P. S.; Thakor, N. V.; Oyler, G. A. Parkin Facilitates the Elimination of Expanded Polyglutamine Proteins and Leads to Preservation of Proteasome Function. J. Biol. Chem. 2003, 278 (24), 22044-22055. 
(82) Stürner, E.; Behl, C. The Role of the Multifunctional BAG3 Protein in Cellular Protein Quality Control and in Disease. Front. Mol. Neurosci. 2017, 10, 177.

(83) Carra, S.; Seguin, S. J.; Landry, J. HspB8 and Bag3: A New Chaperone Complex Targeting Misfolded Proteins to Macroautophagy. Autophagy 2008, 4 (2), 237-239.

(84) Fuchs, M.; Poirier, D. J.; Seguin, S. J.; Lambert, H.; Carra, S.; Charette, S. J.; Landry, J. Identification of the Key Structural Motifs Involved in HspB8/HspB6-Bag3 Interaction. Biochem. J. 2009, 425 (1), 245-255.

(85) Ciechanover, A.; Kwon, Y. T. Degradation of Misfolded Proteins in Neurodegenerative Diseases: Therapeutic Targets and Strategies. Exp. Mol. Med. 2015, 47, e147.

(86) Wyant, K. J.; Ridder, A. J.; Dayalu, P. Huntington's Disease-Update on Treatments. Curr. Neurol. Neurosci. Rep. 2017, 17 (4), 33.

(87) Wild, E. J.; Tabrizi, S. J. Therapies Targeting DNA and RNA in Huntington's Disease. Lancet Neurol. 2017, 16 (10), 837-847.

(88) Richardson, P. G.; Mitsiades, C.; Hideshima, T.; Anderson, K. C. Bortezomib: Proteasome Inhibition as an Effective Anticancer Therapy. Annu. Rev. Med. 2006, 57, 33-47.

(89) Hideshima, T.; Bradner, J. E.; Wong, J.; Chauhan, D.; Richardson, P.; Schreiber, S. L.; Anderson, K. C. Small-Molecule Inhibition of Proteasome and Aggresome Function Induces Synergistic Antitumor Activity in Multiple Myeloma. Proc. Natl. Acad. Sci. U. S. A. 2005, 102 (24), 85678572.

(90) Liu, Y.; Hettinger, C. L.; Zhang, D.; Rezvani, K.; Wang, X.; Wang, H. Sulforaphane Enhances Proteasomal and Autophagic Activities in Mice and Is a Potential Therapeutic Reagent for Huntington's Disease. J. Neurochem. 2014, 129 (3), 539-547.

(91) Jang, M.; Cho, I.-H. Sulforaphane Ameliorates 3-Nitropropionic Acid-Induced Striatal Toxicity by Activating the Keap1-Nrf2-ARE Pathway and Inhibiting the MAPKs and NF-KB Pathways. Mol. Neurobiol. 2016, 53 (4), 2619-2635.

(92) Luis-García, E. R.; Limón-Pacheco, J. H.; Serrano-García, N.; Hernández-Pérez, A. D.; PedrazaChaverri, J.; Orozco-Ibarra, M. Sulforaphane Prevents Quinolinic Acid-Induced Mitochondrial Dysfunction in Rat Striatum. J. Biochem. Mol. Toxicol. 2017, 31 (2).

(93) DeMarch, Z.; Giampà, C.; Patassini, S.; Bernardi, G.; Fusco, F. R. Beneficial Effects of Rolipram in the R6/2 Mouse Model of Huntington's Disease. Neurobiol. Dis. 2008, 30 (3), 375-387.

(94) Berkers, C. R.; van Leeuwen, F. W. B.; Groothuis, T. A.; Peperzak, V.; van Tilburg, E. W.; Borst, J.; Neefjes, J. J.; Ovaa, H. Profiling Proteasome Activity in Tissue with Fluorescent Probes. Mol. Pharm. 2007, 4 (5), 739-748.

(95) Leestemaker, Y.; de Jong, A.; Witting, K. F.; Penning, R.; Schuurman, K.; Rodenko, B.; Zaal, E. A.; van de Kooij, B.; Laufer, S.; Heck, A. J. R.; Borst, J.; Scheper, W.; Berkers, C. R.; Ovaa, H. Proteasome Activation by Small Molecules. Cell Chem. Biol. 2017, 24 (6), 725-736.e7.

(96) Taylor, D. M.; Moser, R.; Régulier, E.; Breuillaud, L.; Dixon, M.; Beesen, A. A.; Elliston, L.; Silva Santos, M. de F.; Kim, J.; Jones, L.; Goldstein, D. R.; Ferrante, R. J.; Luthi-Carter, R. MAP Kinase Phosphatase 1 (MKP-1/DUSP1) Is Neuroprotective in Huntington's Disease via Additive Effects of JNK and p38 Inhibition. J. Neurosci. Off. J. Soc. Neurosci. 2013, 33 (6), 2313-2325.

(97) Wong, H. K.; Bauer, P. O.; Kurosawa, M.; Goswami, A.; Washizu, C.; Machida, Y.; Tosaki, A.; Yamada, M.; Knöpfel, T.; Nakamura, T.; Nukina, N. Blocking Acid-Sensing lon Channel 1 Alleviates Huntington's Disease Pathology via an Ubiquitin-Proteasome System-Dependent Mechanism. Hum. Mol. Genet. 2008, 17 (20), 3223-3235.

(98) Lee, B.-H.; Lee, M. J.; Park, S.; Oh, D.-C.; Elsasser, S.; Chen, P.-C.; Gartner, C.; Dimova, N.; Hanna, J.; Gygi, S. P.; Wilson, S. M.; King, R. W.; Finley, D. Enhancement of Proteasome Activity by a Small-Molecule Inhibitor of USP14. Nature 2010, 467 (7312), 179-184. 
(99) Boselli, M.; Lee, B.-H.; Robert, J.; Prado, M. A.; Min, S.-W.; Cheng, C.; Silva, M. C.; Seong, C.; Elsasser, S.; Hatle, K. M.; Gahman, T. C.; Gygi, S. P.; Haggarty, S. J.; Gan, L.; King, R. W.; Finley, D. An Inhibitor of the Proteasomal Deubiquitinating Enzyme USP14 Induces Tau Elimination in Cultured Neurons. J. Biol. Chem. 2017.

(100) Kiprowska, M. J.; Stepanova, A.; Todaro, D. R.; Galkin, A.; Haas, A.; Wilson, S. M.; FigueiredoPereira, M. E. Neurotoxic Mechanisms by Which the USP14 Inhibitor IU1 Depletes Ubiquitinated Proteins and Tau in Rat Cerebral Cortical Neurons: Relevance to Alzheimer's Disease. Biochim. Biophys. Acta 2017, 1863 (6), 1157-1170.

(101) Sarkar, S.; Krishna, G.; Imarisio, S.; Saiki, S.; O’Kane, C. J.; Rubinsztein, D. C. A Rational Mechanism for Combination Treatment of Huntington's Disease Using Lithium and Rapamycin. Hum. Mol. Genet. 2008, 17 (2), 170-178.

(102) DeBosch, B. J.; Heitmeier, M. R.; Mayer, A. L.; Higgins, C. B.; Crowley, J. R.; Kraft, T. E.; Chi, M.; Newberry, E. P.; Chen, Z.; Finck, B. N.; Davidson, N. O.; Yarasheski, K. E.; Hruz, P. W.; Moley, K. H. Trehalose Inhibits Solute Carrier 2A (SLC2A) Proteins to Induce Autophagy and Prevent Hepatic Steatosis. Sci. Signal. 2016, 9 (416), ra21.

(103) Mardones, P.; Rubinsztein, D. C.; Hetz, C. Mystery Solved: Trehalose Kickstarts Autophagy by Blocking Glucose Transport. Sci. Signal. 2016, 9 (416), fs2.

(104) Sarkar, S.; Davies, J. E.; Huang, Z.; Tunnacliffe, A.; Rubinsztein, D. C. Trehalose, a Novel mTORIndependent Autophagy Enhancer, Accelerates the Clearance of Mutant Huntingtin and AlphaSynuclein. J. Biol. Chem. 2007, 282 (8), 5641-5652.

(105) Tanaka, M.; Machida, Y.; Niu, S.; Ikeda, T.; Jana, N. R.; Doi, H.; Kurosawa, M.; Nekooki, M.; Nukina, N. Trehalose Alleviates Polyglutamine-Mediated Pathology in a Mouse Model of Huntington Disease. Nat. Med. 2004, 10 (2), 148-154.

(106) Fernandez-Estevez, M. A.; Casarejos, M. J.; López Sendon, J.; Garcia Caldentey, J.; Ruiz, C.; Gomez, A.; Perucho, J.; de Yebenes, J. G.; Mena, M. A. Trehalose Reverses Cell Malfunction in Fibroblasts from Normal and Huntington's Disease Patients Caused by Proteosome Inhibition. PloS One 2014, 9 (2), e90202.

(107) Rose, C.; Menzies, F. M.; Renna, M.; Acevedo-Arozena, A.; Corrochano, S.; Sadiq, O.; Brown, S. D.; Rubinsztein, D. C. Rilmenidine Attenuates Toxicity of Polyglutamine Expansions in a Mouse Model of Huntington's Disease. Hum. Mol. Genet. 2010, 19 (11), 2144-2153.

(108) Sarkar, S.; Rubinsztein, D. C. Inositol and IP3 Levels Regulate Autophagy: Biology and Therapeutic Speculations. Autophagy 2006, 2 (2), 132-134.

(109) Sarkar, S.; Krishna, G.; Imarisio, S.; Saiki, S.; O’Kane, C. J.; Rubinsztein, D. C. A Rational Mechanism for Combination Treatment of Huntington's Disease Using Lithium and Rapamycin. Hum. Mol. Genet. 2008, $17(2), 170-178$.

(110) Jiang, W.; Wei, W.; Gaertig, M. A.; Li, S.; Li, X.-J. Therapeutic Effect of Berberine on Huntington's Disease Transgenic Mouse Model. PloS One 2015, 10 (7), e0134142.

(111) Ahmed, T.; Gilani, A.-U.-H.; Abdollahi, M.; Daglia, M.; Nabavi, S. F.; Nabavi, S. M. Berberine and Neurodegeneration: A Review of Literature. Pharmacol. Rep. PR 2015, 67 (5), 970-979.

(112) Williams, A.; Sarkar, S.; Cuddon, P.; Ttofi, E. K.; Saiki, S.; Siddiqi, F. H.; Jahreiss, L.; Fleming, A.; Pask, D.; Goldsmith, P.; O'Kane, C. J.; Floto, R. A.; Rubinsztein, D. C. Novel Targets for Huntington's Disease in an mTOR-Independent Autophagy Pathway. Nat. Chem. Biol. 2008, 4 (5), 295-305.

(113) Menzies, F. M.; Garcia-Arencibia, M.; Imarisio, S.; O'Sullivan, N. C.; Ricketts, T.; Kent, B. A.; Rao, M. V.; Lam, W.; Green-Thompson, Z. W.; Nixon, R. A.; Saksida, L. M.; Bussey, T. J.; O'Kane, C. J.; Rubinsztein, D. C. Calpain Inhibition Mediates Autophagy-Dependent Protection against Polyglutamine Toxicity. Cell Death Differ. 2015, 22 (3), 433-444. 
(114) Jin, J.; Gu, H.; Anders, N. M.; Ren, T.; Jiang, M.; Tao, M.; Peng, Q.; Rudek, M. A.; Duan, W. Metformin Protects Cells from Mutant Huntingtin Toxicity Through Activation of AMPK and Modulation of Mitochondrial Dynamics. Neuromolecular Med. 2016, 18 (4), 581-592.

(115) Vázquez-Manrique, R. P.; Farina, F.; Cambon, K.; Dolores Sequedo, M.; Parker, A. J.; Millán, J. M.; Weiss, A.; Déglon, N.; Neri, C. AMPK Activation Protects from Neuronal Dysfunction and Vulnerability across Nematode, Cellular and Mouse Models of Huntington's Disease. Hum. Mol. Genet. 2016, 25 (6), 1043-1058.

(116) Hervás, D.; Fornés-Ferrer, V.; Gómez-Escribano, A. P.; Sequedo, M. D.; Peiró, C.; Millán, J. M.; Vázquez-Manrique, R. P. Metformin Intake Associates with Better Cognitive Function in Patients with Huntington's Disease. PloS One 2017, 12 (6), e0179283.

(117) Menzies, F. M.; Fleming, A.; Caricasole, A.; Bento, C. F.; Andrews, S. P.; Ashkenazi, A.; Füllgrabe, J.; Jackson, A.; Jimenez Sanchez, M.; Karabiyik, C.; Licitra, F.; Lopez Ramirez, A.; Pavel, M.; Puri, C.; Renna, M.; Ricketts, T.; Schlotawa, L.; Vicinanza, M.; Won, H.; Zhu, Y.; Skidmore, J.; Rubinsztein, D. C. Autophagy and Neurodegeneration: Pathogenic Mechanisms and Therapeutic Opportunities. Neuron 2017, 93 (5), 1015-1034.

(118) Herbst, M.; Wanker, E. E. Small Molecule Inducers of Heat-Shock Response Reduce polyQMediated Huntingtin Aggregation. A Possible Therapeutic Strategy. Neurodegener. Dis. 2007, 4 (2-3), 254-260.

(119) Labbadia, J.; Cunliffe, H.; Weiss, A.; Katsyuba, E.; Sathasivam, K.; Seredenina, T.; Woodman, B.; Moussaoui, S.; Frentzel, S.; Luthi-Carter, R.; Paganetti, P.; Bates, G. P. Altered Chromatin Architecture Underlies Progressive Impairment of the Heat Shock Response in Mouse Models of Huntington Disease. J. Clin. Invest. 2011, 121 (8), 3306-3319.

(120) Fujikake, N.; Nagai, Y.; Popiel, H. A.; Okamoto, Y.; Yamaguchi, M.; Toda, T. Heat Shock Transcription Factor 1-Activating Compounds Suppress Polyglutamine-Induced Neurodegeneration through Induction of Multiple Molecular Chaperones. J. Biol. Chem. 2008, 283 (38), 26188-26197.

(121) Luo, W.; Dou, F.; Rodina, A.; Chip, S.; Kim, J.; Zhao, Q.; Moulick, K.; Aguirre, J.; Wu, N.; Greengard, P.; Chiosis, G. Roles of Heat-Shock Protein 90 in Maintaining and Facilitating the Neurodegenerative Phenotype in Tauopathies. Proc. Natl. Acad. Sci. U. S. A. 2007, 104 (22), 9511-9516.

(122) Ernst, J. T.; Neubert, T.; Liu, M.; Sperry, S.; Zuccola, H.; Turnbull, A.; Fleck, B.; Kargo, W.; Woody, L.; Chiang, P.; Tran, D.; Chen, W.; Snyder, P.; Alcacio, T.; Nezami, A.; Reynolds, J.; Alvi, K.; Goulet, L.; Stamos, D. Identification of Novel HSP90 $\alpha / \beta$ Isoform Selective Inhibitors Using StructureBased Drug Design. Demonstration of Potential Utility in Treating CNS Disorders such as Huntington's Disease. J. Med. Chem. 2014, 57 (8), 3382-3400.

(123) Zhang, Y.-Q.; Sarge, K. D. Celastrol Inhibits Polyglutamine Aggregation and Toxicity Though Induction of the Heat Shock Response. J. Mol. Med. Berl. Ger. 2007, 85 (12), 1421-1428.

(124) Sakamoto, K. M.; Kim, K. B.; Kumagai, A.; Mercurio, F.; Crews, C. M.; Deshaies, R. J. Protacs: Chimeric Molecules That Target Proteins to the Skp1-Cullin-F Box Complex for Ubiquitination and Degradation. Proc. Natl. Acad. Sci. U. S. A. 2001, 98 (15), 8554-8559.

(125) Deshaies, R. J. Protein Degradation: Prime Time for PROTACs. Nat. Chem. Biol. 2015, 11 (9), 634635.

(126) Tomoshige, S.; Nomura, S.; Ohgane, K.; Hashimoto, Y.; Ishikawa, M. Discovery of Small Molecules That Induce the Degradation of Huntingtin. Angew. Chem. Int. Ed Engl. 2017, 56 (38), 1153011533.

(127) Wray, S.; Self, M.; NINDS Parkinson's Disease iPSC Consortium; NINDS Huntington's Disease iPSC Consortium; NINDS ALS iPSC Consortium; Lewis, P. A.; Taanman, J.-W.; Ryan, N. S.; Mahoney, C. J.; Liang, Y.; Devine, M. J.; Sheerin, U.-M.; Houlden, H.; Morris, H. R.; Healy, D.; Marti-Masso, J.- 
F.; Preza, E.; Barker, S.; Sutherland, M.; Corriveau, R. A.; D'Andrea, M.; Schapira, A. H. V.; Uitti, R. J.; Guttman, M.; Opala, G.; Jasinska-Myga, B.; Puschmann, A.; Nilsson, C.; Espay, A. J.; Slawek, J.; Gutmann, L.; Boeve, B. F.; Boylan, K.; Stoessl, A. J.; Ross, O. A.; Maragakis, N. J.; Van Gerpen, J.; Gerstenhaber, M.; Gwinn, K.; Dawson, T. M.; Isacson, O.; Marder, K. S.; Clark, L. N.; Przedborski, S. E.; Finkbeiner, S.; Rothstein, J. D.; Wszolek, Z. K.; Rossor, M. N.; Hardy, J. Creation of an OpenAccess, Mutation-Defined Fibroblast Resource for Neurological Disease Research. PloS One 2012, 7 (8), e43099.

(128) Tanji, K.; Kamitani, T.; Mori, F.; Kakita, A.; Takahashi, H.; Wakabayashi, K. TRIM9, a Novel BrainSpecific E3 Ubiquitin Ligase, Is Repressed in the Brain of Parkinson's Disease and Dementia with Lewy Bodies. Neurobiol. Dis. 2010, 38 (2), 210-218.

(129) Liu, Q. Y.; Lei, J. X.; Sikorska, M.; Liu, R. A Novel Brain-Enriched E3 Ubiquitin Ligase RNF182 Is up Regulated in the Brains of Alzheimer's Patients and Targets ATP6VOC for Degradation. Mol. Neurodegener. 2008, 3, 4.

(130) Itoh, Y.; Ishikawa, M.; Kitaguchi, R.; Sato, S.; Naito, M.; Hashimoto, Y. Development of Target Protein-Selective Degradation Inducer for Protein Knockdown. Bioorg. Med. Chem. 2011, 19 (10), 3229-3241.

(131) Ottis, P.; Crews, C. M. Proteolysis-Targeting Chimeras: Induced Protein Degradation as a Therapeutic Strategy. ACS Chem. Biol. 2017, 12 (4), 892-898.

(132) Burslem, G. M.; Crews, C. M. Small-Molecule Modulation of Protein Homeostasis. Chem. Rev. 2017, 117 (17), 11269-11301.

(133) Matsumura, K.; Ono, M.; Hayashi, S.; Kimura, H.; Okamoto, Y.; Ihara, M.; Takahashi, R.; Mori, H.; Saji, H. Phenyldiazenyl Benzothiazole Derivatives as Probes for in Vivo Imaging of Neurofibrillary Tangles in Alzheimer's Disease Brains. MedChemComm 2011, 2 (7), 596-600.

(134) Klunk, W. E.; Wang, Y.; Huang, G.; Debnath, M. L.; Holt, D. P.; Mathis, C. A. Uncharged Thioflavin-T Derivatives Bind to Amyloid-Beta Protein with High Affinity and Readily Enter the Brain. Life Sci. 2001, 69 (13), 1471-1484.

(135) Genetic Modifiers of Huntington's Disease (GeM-HD) Consortium. Identification of Genetic Factors That Modify Clinical Onset of Huntington's Disease. Cell 2015, 162 (3), 516-526.

(136) Tomaic, V.; Pim, D.; Thomas, M.; Massimi, P.; Myers, M. P.; Banks, L. Regulation of the Human Papillomavirus Type 18 E6/E6AP Ubiquitin Ligase Complex by the HECT Domain-Containing Protein EDD. J. Virol. 2011, 85 (7), 3120-3127.

(137) Jiang, W.; Wang, S.; Xiao, M.; Lin, Y.; Zhou, L.; Lei, Q.; Xiong, Y.; Guan, K.-L.; Zhao, S. Acetylation Regulates Gluconeogenesis by Promoting PEPCK1 Degradation via Recruiting the UBR5 Ubiquitin Ligase. Mol. Cell 2011, 43 (1), 33-44.

(138) Zhang, T.; Cronshaw, J.; Kanu, N.; Snijders, A. P.; Behrens, A. UBR5-Mediated Ubiquitination of ATMIN Is Required for lonizing Radiation-Induced ATM Signaling and Function. Proc. Natl. Acad. Sci. U. S. A. 2014, 111 (33), 12091-12096.

(139) Ling, S.; Lin, W.-C. EDD Inhibits ATM-Mediated Phosphorylation of p53. J. Biol. Chem. 2011, 286 (17), 14972-14982.

(140) Travessa, A. M.; Rodrigues, F. B.; Mestre, T. A.; Ferreira, J. J. Fifteen Years of Clinical Trials in Huntington's Disease: A Very Low Clinical Drug Development Success Rate. J. Huntingt. Dis. 2017, 6 (2), 157-163.

(141) Garbaccio, R. M.; Parmee, E. R. The Impact of Chemical Probes in Drug Discovery: A Pharmaceutical Industry Perspective. Cell Chem. Biol. 2016, 23 (1), 10-17.

(142) Mukhopadhyay, S.; Frias, M. A.; Chatterjee, A.; Yellen, P.; Foster, D. A. The Enigma of Rapamycin Dosage. Mol. Cancer Ther. 2016, 15 (3), 347-353.

(143) Bové, J.; Martínez-Vicente, M.; Vila, M. Fighting Neurodegeneration with Rapamycin: Mechanistic Insights. Nat. Rev. Neurosci. 2011, 12 (8), 437-452. 
(144) Arrowsmith, C. H.; Audia, J. E.; Austin, C.; Baell, J.; Bennett, J.; Blagg, J.; Bountra, C.; Brennan, P. E.; Brown, P. J.; Bunnage, M. E.; Buser-Doepner, C.; Campbell, R. M.; Carter, A. J.; Cohen, P.; Copeland, R. A.; Cravatt, B.; Dahlin, J. L.; Dhanak, D.; Edwards, A. M.; Frederiksen, M.; Frye, S. V.; Gray, N.; Grimshaw, C. E.; Hepworth, D.; Howe, T.; Huber, K. V. M.; Jin, J.; Knapp, S.; Kotz, J. D.; Kruger, R. G.; Lowe, D.; Mader, M. M.; Marsden, B.; Mueller-Fahrnow, A.; Müller, S.; O'Hagan, R. C.; Overington, J. P.; Owen, D. R.; Rosenberg, S. H.; Ross, R.; Roth, B.; Schapira, M.; Schreiber, S. L.; Shoichet, B.; Sundström, M.; Superti-Furga, G.; Taunton, J.; Toledo-Sherman, L.; Walpole, C.; Walters, M. A.; Willson, T. M.; Workman, P.; Young, R. N.; Zuercher, W. J. The Promise and Peril of Chemical Probes. Nat. Chem. Biol. 2015, 11 (8), 536-541.

(145) Workman, P.; Collins, I. Probing the Probes: Fitness Factors For Small Molecule Tools. Chem. Biol. 2010, $17(6), 561-577$.

(146) Bunnage, M. E.; Chekler, E. L. P.; Jones, L. H. Target Validation Using Chemical Probes. Nat. Chem. Biol. 2013, 9 (4), 195-199.

(147) Frigault, M. M.; Barrett, J. C. Is Target Validation All We Need? Curr. Opin. Pharmacol. 2014, 17, 81-86.

(148) Alguacil, L. F.; González-Martín, C. Target Identification and Validation in Brain Reward Dysfunction. Drug Discov. Today 2015, 20 (3), 347-352.

(149) Zhang, W.; Wu, K.-P.; Sartori, M. A.; Kamadurai, H. B.; Ordureau, A.; Jiang, C.; Mercredi, P. Y.; Murchie, R.; Hu, J.; Persaud, A.; Mukherjee, M.; Li, N.; Doye, A.; Walker, J. R.; Sheng, Y.; Hao, Z.; Li, Y.; Brown, K. R.; Lemichez, E.; Chen, J.; Tong, Y.; Harper, J. W.; Moffat, J.; Rotin, D.; Schulman, B. A.; Sidhu, S. S. System-Wide Modulation of HECT E3 Ligases with Selective Ubiquitin Variant Probes. Mol. Cell 2016, 62 (1), 121-136.

(150) Ernst, A.; Avvakumov, G.; Tong, J.; Fan, Y.; Zhao, Y.; Alberts, P.; Persaud, A.; Walker, J. R.; Neculai, A.-M.; Neculai, D.; Vorobyov, A.; Garg, P.; Beatty, L.; Chan, P.-K.; Juang, Y.-C.; Landry, M.-C.; Yeh, C.; Zeqiraj, E.; Karamboulas, K.; Allali-Hassani, A.; Vedadi, M.; Tyers, M.; Moffat, J.; Sicheri, F.; Pelletier, L.; Durocher, D.; Raught, B.; Rotin, D.; Yang, J.; Moran, M. F.; Dhe-Paganon, S.; Sidhu, S. S. A Strategy for Modulation of Enzymes in the Ubiquitin System. Science 2013, 339 (6119), 590-595.

(151) Lu, K.; Brave, F. den; Jentsch, S. Pathway Choice between Proteasomal and Autophagic Degradation. Autophagy 2017, 13 (10), 1799-1800.

(152) Majumder, S.; Richardson, A.; Strong, R.; Oddo, S. Inducing Autophagy by Rapamycin Before, but Not After, the Formation of Plaques and Tangles Ameliorates Cognitive Deficits. PLOS ONE 2011, $6(9)$.

(153) Li, J. Y.; Popovic, N.; Brundin, P. The Use of the R6 Transgenic Mouse Models of Huntington's Disease in Attempts to Develop Novel Therapeutic Strategies. NeuroRx 2005, 2 (3), 447-464.

(154) Gray, M.; Shirasaki, D. I.; Cepeda, C.; André, V. M.; Wilburn, B.; Lu, X.-H.; Tao, J.; Yamazaki, I.; Li, S.-H.; Sun, Y. E.; Li, X.-J.; Levine, M. S.; Yang, X. W. Full-Length Human Mutant Huntingtin with a Stable Polyglutamine Repeat Can Elicit Progressive and Selective Neuropathogenesis in BACHD Mice. J. Neurosci. 2008, 28 (24), 6182-6195.

(155) Slow, E. J.; van Raamsdonk, J.; Rogers, D.; Coleman, S. H.; Graham, R. K.; Deng, Y.; Oh, R.; Bissada, N.; Hossain, S. M.; Yang, Y.-Z.; Li, X.-J.; Simpson, E. M.; Gutekunst, C.-A.; Leavitt, B. R.; Hayden, M. R. Selective Striatal Neuronal Loss in a YAC128 Mouse Model of Huntington Disease. Hum. Mol. Genet. 2003, 12 (13), 1555-1567.

(156) Mattis, V. B.; Tom, C.; Akimov, S.; Saeedian, J.; Østergaard, M. E.; Southwell, A. L.; Doty, C. N.; Ornelas, L.; Sahabian, A.; Lenaeus, L.; Mandefro, B.; Sareen, D.; Arjomand, J.; Hayden, M. R.; Ross, C. A.; Svendsen, C. N. HD iPSC-Derived Neural Progenitors Accumulate in Culture and Are Susceptible to BDNF Withdrawal due to Glutamate Toxicity. Hum. Mol. Genet. 2015, 24 (11), 3257-3271. 
(157) HD iPSC Consortium. Induced Pluripotent Stem Cells from Patients with Huntington's Disease Show CAG-Repeat-Expansion-Associated Phenotypes. Cell Stem Cell 2012, 11 (2), 264-278.

(158) Cheng, P.-H.; Li, C.-L.; Chang, Y.-F.; Tsai, S.-J.; Lai, Y.-Y.; Chan, A. W. S.; Chen, C.-M.; Yang, S.-H. miR-196a Ameliorates Phenotypes of Huntington Disease in Cell, Transgenic Mouse, and Induced Pluripotent Stem Cell Models. Am. J. Hum. Genet. 2013, 93 (2), 306-312.

(159) Ravikumar, B.; Duden, R.; Rubinsztein, D. C. Aggregate-Prone Proteins with Polyglutamine and Polyalanine Expansions Are Degraded by Autophagy. Hum. Mol. Genet. 2002, 11 (9), 1107-1117.

(160) Malagelada, C.; Jin, Z. H.; Jackson-Lewis, V.; Przedborski, S.; Greene., L. A. Rapamycin Protects Against Neuron Death In in Vitro and in Vivo Models of Parkinson's Disease. J. Neurosci. Off. J. Soc. Neurosci. 2010, 30 (3), 1166-1175.

(161) Zhang, X.; Li, L.; Chen, S.; Yang, D.; Wang, Y.; Zhang, X.; Wang, Z.; Le, W. Rapamycin Treatment Augments Motor Neuron Degeneration in SOD1(G93A) Mouse Model of Amyotrophic Lateral Sclerosis. Autophagy 2011, 7 (4), 412-425.

(162) Federico, C. A.; Carlisle, B.; Kimmelman, J.; Fergusson, D. A. Late, Never or Non-Existent: The Inaccessibility of Preclinical Evidence for New Drugs. Br. J. Pharmacol. 2014, 171 (18), 42474254.

(163) Kumarapeli, A. R. K.; Horak, K. M.; Glasford, J. W.; Li, J.; Chen, Q.; Liu, J.; Zheng, H.; Wang, X. A Novel Transgenic Mouse Model Reveals Deregulation of the Ubiquitin-Proteasome System in the Heart by Doxorubicin. FASEB J. Off. Publ. Fed. Am. Soc. Exp. Biol. 2005, 19 (14), 2051-2053.

(164) Ahmed, T.; Gilani, A.-U.-H.; Abdollahi, M.; Daglia, M.; Nabavi, S. F.; Nabavi, S. M. Berberine and Neurodegeneration: A Review of Literature. Pharmacol. Rep. PR 2015, 67 (5), 970-979. 


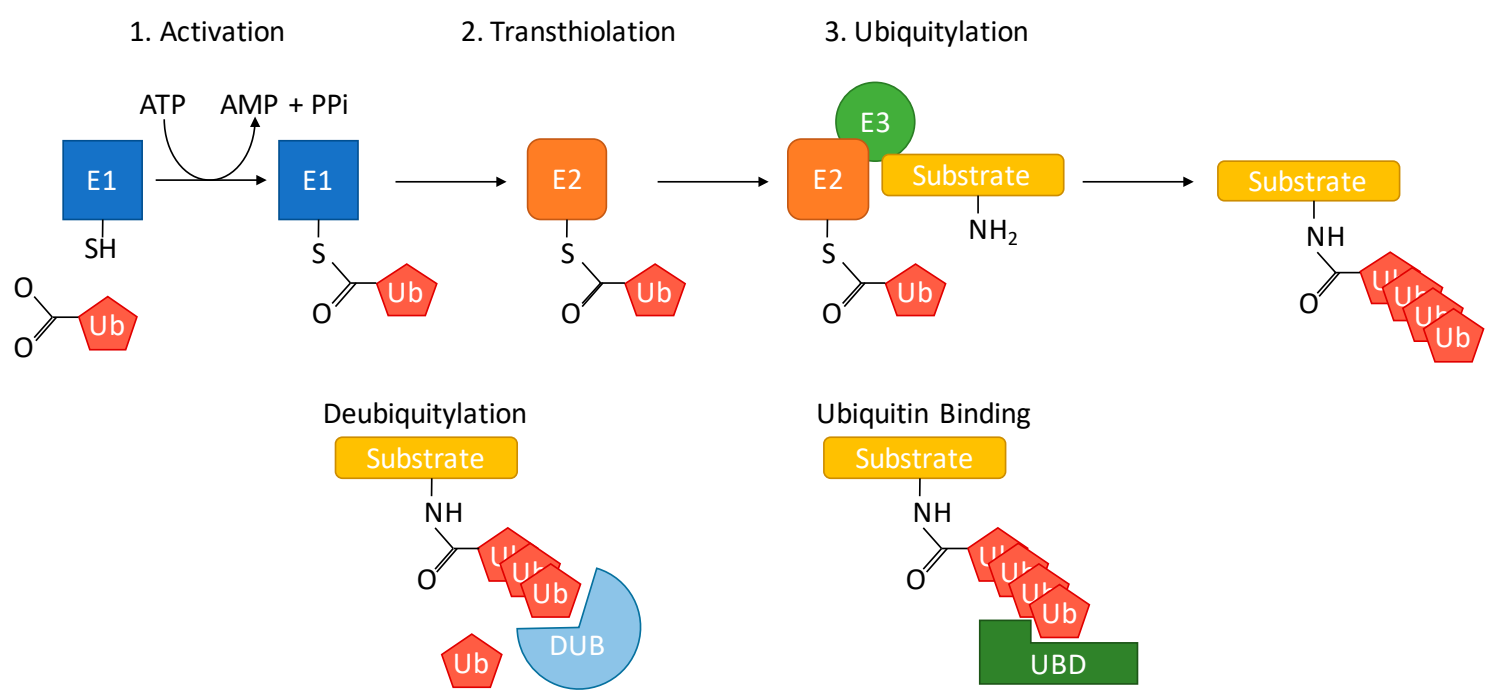

Figure 1. Overview of the ubiquitin protein system

Target proteins are ubiquitylated at accessible lysine residues by a three-enzyme cascade comprised of a ubiquitin activating enzyme (E1), a conjugating enzyme (E2) and a ubiquitin ligase (E3). Different lysine residues of the tagged ubiquitin can be further polyubiquitinated. The covalently attached ubiquitin modifications can be removed by deubiquitinases (DUBs). Specific covalent linkages of ubiquitin are recognised by a range of proteins containing ubiquitin binding domains (UBDs) or ubiquitin-interacting motifs (UIMs). 


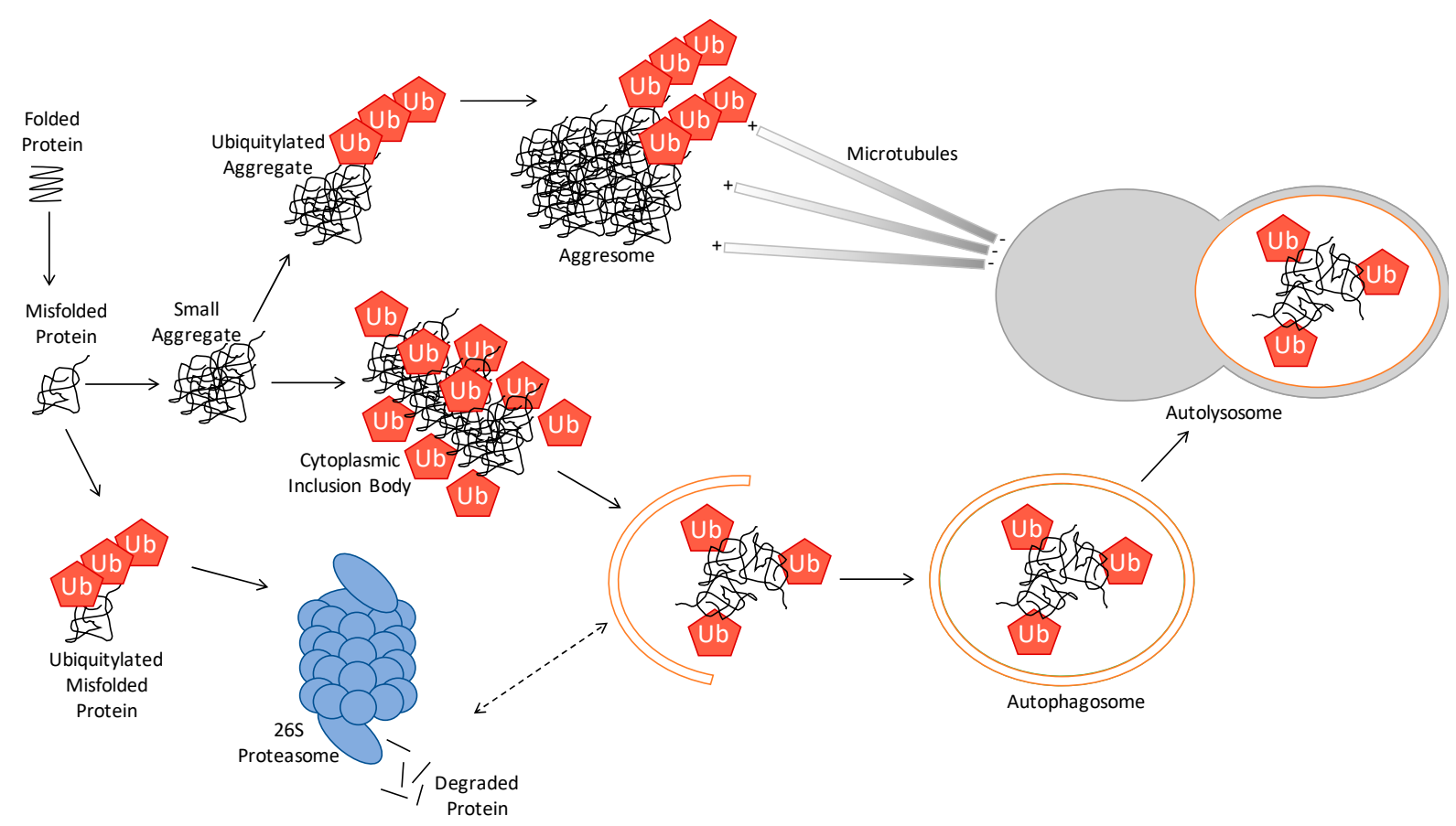

Figure 2-Degradation pathways for $\mathrm{mHTT}$

MHTT misfolding can lead to subsequent aggregation and ubiquitination. Smaller ubiquitinated aggregates may be cleared by the proteasome, whereas larger aggregates which form aggresomes of inclusion bodies will be degraded via autophagic routes. 


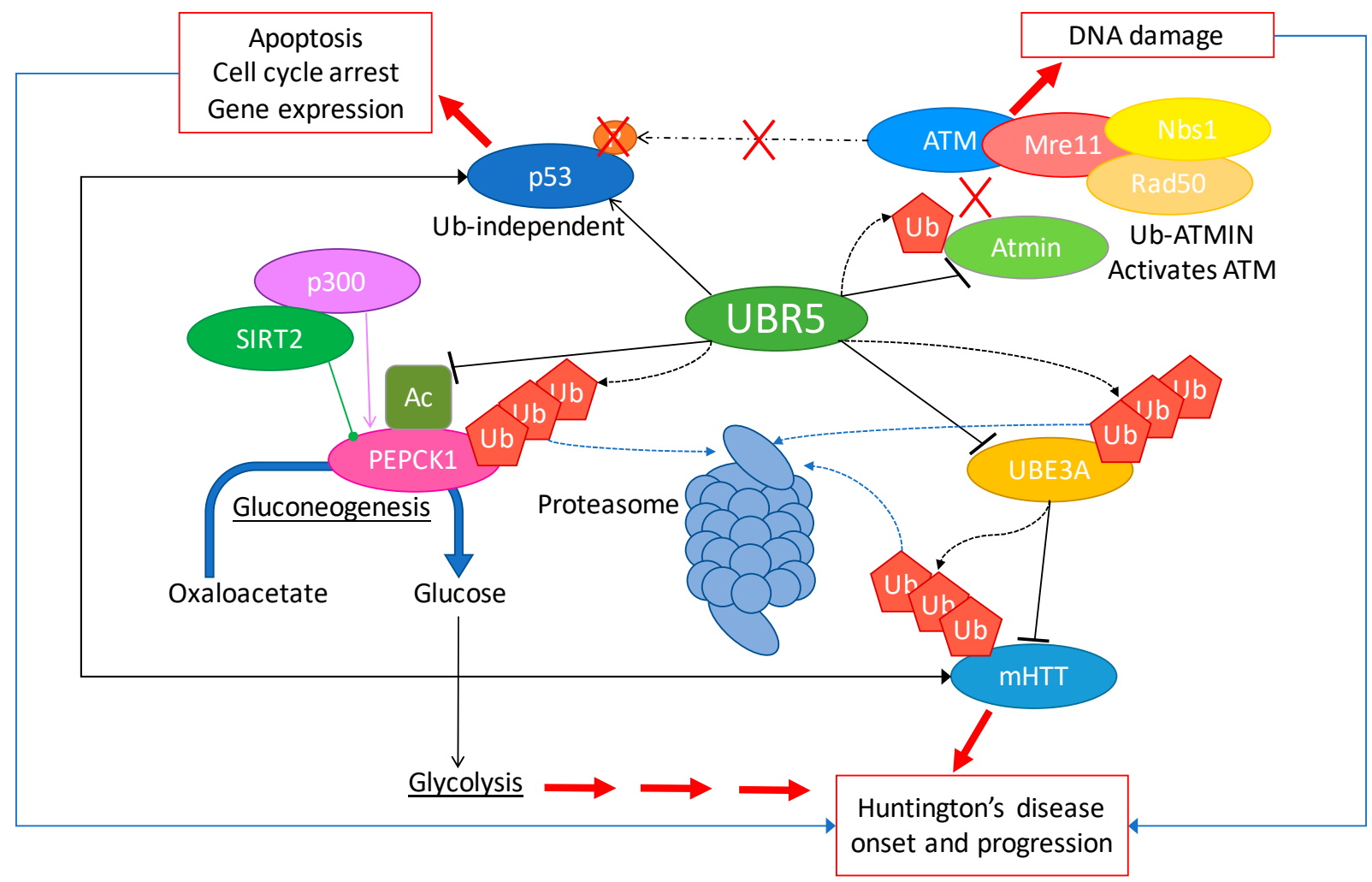

Figure 3-UBR5 is a genetic modifier of HD and plays a multifaceted role in the disease pathways

UBR5 is an E3 ubiquitin ligase with many roles in HD-related pathways. UBR5 can downregulated UBE3a mediated degradation of $\mathrm{mHTT}$, regulate PEPCK1 acetylation modulating gluconeogenesis in prodromal HD, ubiquitinate ATMIN to recruit the MRN complex for DNA damage response and upregulate p53 through ATM-phosphorylation inhibition affecting HTT aggregate formation. As UBR5 plays such a central multi-faceted role in HD phenotype, targeting its activity for inhibition with small molecules seems a tractable therapeutic avenue to be explored. 


\begin{tabular}{|c|c|c|c|}
\hline Therapeutic & Model Evaluated & Pathway and Outcome & References \\
\hline Sulforphane & $\begin{array}{l}\text { HeLa and HEK293 cells - express HTT exon } 1 \text { Q74 } \\
\text { GFPu transgenic UPS function model mouse }{ }^{163} \text { - express mouse HTT } \\
\text { HD51 Rat - N-terminal HTT fragment Q51 } \\
\text { 3-nitroproprionic acid-induced HD mouse (C57BL/6) - express mouse HTT }\end{array}$ & $\begin{array}{l}\text { Activate Keap1-Nrf2-ARE pathways and } \\
\text { inhibiting MAPK and NF-kB pathways to activate } \\
\text { autophagy and UPS }\end{array}$ & \begin{tabular}{|l|}
$90-92$ \\
\end{tabular} \\
\hline Rolipram & R6/2 mouse $-\mathrm{HTT}$ exon $1 \mathrm{Q} 150$ & $\begin{array}{l}\text { inhibits phosphodiesterase } 4 \text { activating protein } \\
\text { kinase } A \text { to activate UPS }\end{array}$ & 93 \\
\hline IU1 & Alzheimer's disease models & $\begin{array}{l}\text { Inhibit USP14 to inhibit deubiquitination of UPS } \\
\text { substrates }\end{array}$ & 100 \\
\hline $\begin{array}{l}\text { Amiloride, } \\
\text { Benzamil }\end{array}$ & $\begin{array}{l}\text { Neuro2a cells - express N-terminal HTT Q16-EGFP, Q60-EGFP or Q150-EGFP } \\
\text { R6/2 mouse - HTT exon } 1 \text { Q150 }\end{array}$ & $\begin{array}{l}\text { Rescue acid-sensing ion channel (ASIC)- } \\
\text { dependent acidotoxicity which inhibits UPS }\end{array}$ & 97 \\
\hline $\begin{array}{l}\text { Rapamycin, } \\
\text { CCl-779 }\end{array}$ & $\begin{array}{l}\text { COS7 and PC12 cells - HTT exon } 1 \text { Q23-EGFP or Q74-EGFP } \\
\text { Drosophila - N-terminal HTT fragment Q120 } \\
\text { N171-82Q mouse - N-terminal HTT fragment Q82 }\end{array}$ & $\begin{array}{l}\text { Inhibit mammalian target of rapamycin (mTOR) } \\
\text { to activate autophagy }\end{array}$ & 70,109 \\
\hline Trehalose & $\begin{array}{l}\text { R6/1 mice - } \mathrm{N} \text {-terminal } \mathrm{HTT} \text { fragment Q116 } \\
\text { R6/2 mouse }-\mathrm{HTT} \text { exon } 1 \text { Q150 } \\
\text { HD patient fibroblasts - express full-length HTT unknown polyQ expansion } \\
\text { Neuro2a cells - express } \mathrm{N} \text {-terminal HTT Q16-EGFP, Q60-EGFP or Q150-EGFP }\end{array}$ & $\begin{array}{l}\text { Activate AMPK by inhibiting glucose } \\
\text { transporters activating autophagy }\end{array}$ & 104-106 \\
\hline $\begin{array}{l}\text { Rilmenidine, } \\
\text { clonidine }\end{array}$ & PC12 cells - full-length EGFP-HTT Q74 & $\begin{array}{l}\text { Imidazoline-1 receptor agonist to reduce cAMP, } \\
\text { mTOR-independent activation of autophagy }\end{array}$ & 107 \\
\hline Lithium & PC12 cells - full-length EGFP-HTT Q74 & $\begin{array}{l}\text { Inhibit IMPase and lower inositol and IP3 levels, } \\
\text { mTOR-independent activation of autophagy }\end{array}$ & 109 \\
\hline Metformin & Striatal cell lines derived from HdhQ111 knock-in mice - full-length HTT Q109 & AMPK activating inducer of autophagy & 114,116 \\
\hline Berberine & N171-82Q mouse - N-terminal HTT fragment Q82 & AMPK activating inducer of autophagy & 110,164 \\
\hline $\begin{array}{l}\text { Geldanamycin, } \\
\text { 17-DMAG, } \\
\text { 17-AAG }\end{array}$ & $\begin{array}{l}\text { Drosophila - N-terminal HTT fragment Q128 } \\
\text { R6/2 mouse - HTT exon } 1 \text { Q150 } \\
\text { COS1 cells - express N-terminal HTT Q51 }\end{array}$ & HSP90 inhibition & $118,120,122$ \\
\hline Celastrol & Striatal cells - full-length HTT Q111 & HSP90 inhibition & 123 \\
\hline PROTAC & HD patient fibroblasts - express full-length HTT Q47 or Q68 & clAP1 mediated UPS degradation of substrate & 126 \\
\hline
\end{tabular}

Table 1 - Summary of therapies detailed in this review and their evaluations in different HD models. 